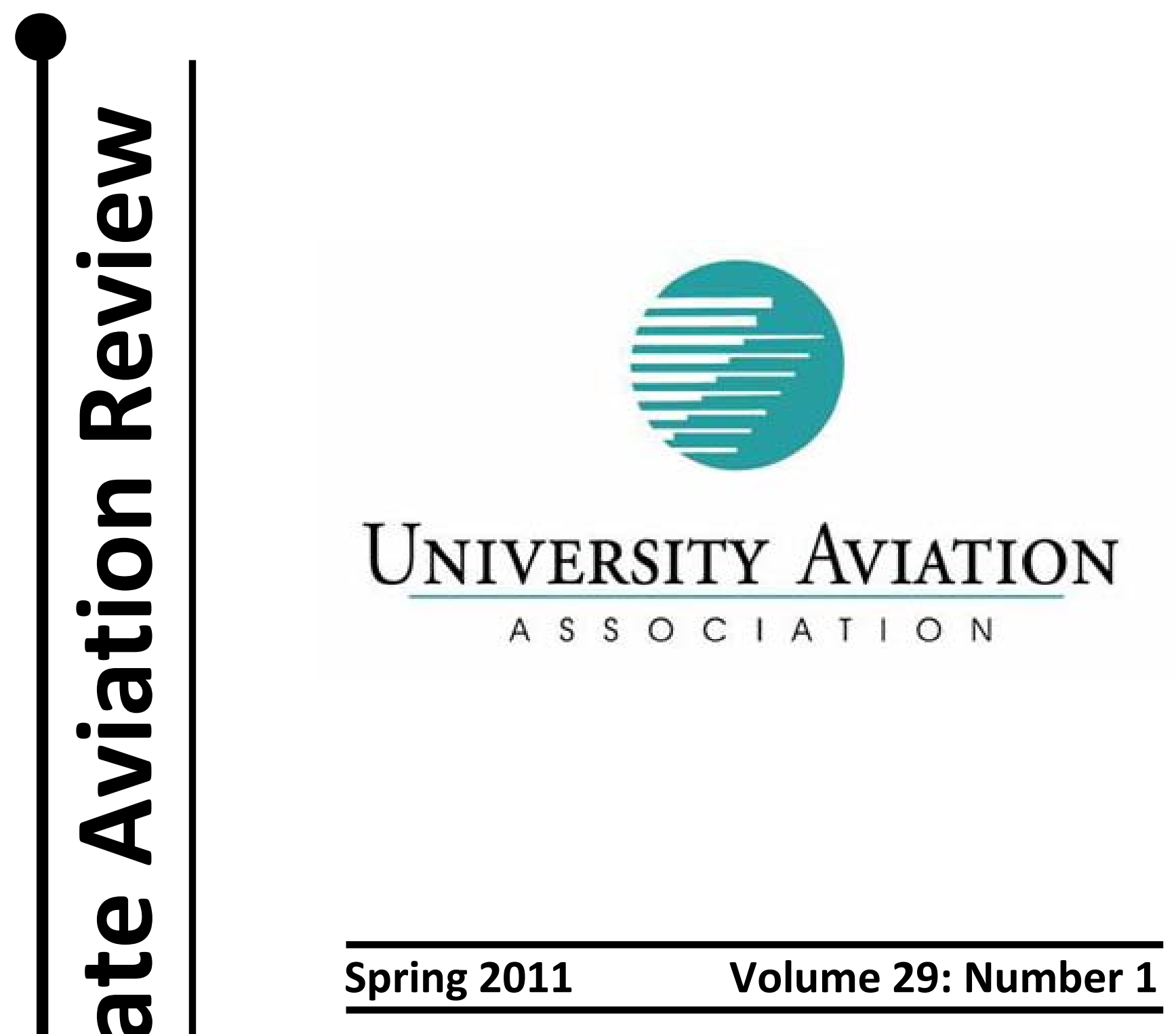




\section{UNIVERSITY AVIATION ASSOCIATION}

\section{COLLEGIATE AVIATION REVIEW}

Wendy S. Beckman, Ed.D., Editor

David C. Ison, Ph.D., Associate Editor 
The Collegiate Aviation Review (CAR)

Spring 2011, Volume 29, Number 1

Wendy S. Beckman, Editor

Copyright (C) 2011 University Aviation Association

All correspondence and inquiries should be directed to:

University Aviation Association

3410 Skyway Drive

Auburn, AL 36830

Telephone: 334-844-2434

Email: uaa@mail.auburn.edu

ISSN Number: 1523-5955 


\section{Editorial Board}

\section{of the}

\section{Collegiate Aviation Review}

Wendy S. Beckman, Middle Tennessee State University, Editor

David C. Ison, Rocky Mountain College, Associate Editor

Timm Bliss, Oklahoma State University

Brent D. Bowen, Purdue University

Thomas Q. Carney, Purdue University

Gerald P. Chubb, The Ohio State University

Wayne A. Dornan, Middle Tennessee State University

Mavis F. Green, Utah Valley University

Todd P. Hubbard, Oklahoma State University

Merrill R. Karp, Arizona State University

William Kohlruss, Embry-Riddle Aeronautical University

Jacqueline R. Luedtke, Embry-Riddle Aeronautical University

David A. NewMyer, Southern Illinois University at Carbondale

Gary J. Northam, Embry-Riddle Aeronautical Univ. - Prescott

Lorelei E. Ruiz, Southern Illinois University at Carbondale

Mark Sherman, New York State University Farmingdale

James L. Simmons, Metropolitan State College of Denver 


\section{ACKNOWLEDGEMENTS}

The University Aviation Association gratefully acknowledges the generosity of Middle Tennessee State University and Purdue University in co-sponsoring this edition of the Collegiate Aviation Review (CAR).

No juried publication can excel, unless experts in the field serve as anonymous reviewers. Indeed, the ultimate guarantors of quality and appropriateness of scholarly materials for a professional journal are the knowledge, integrity, and thoroughness of those who serve in this capacity. The thoughtful, careful, and timely work of the Editorial Board and each of the following professionals added substantively to the quality of the journal, and made the editor's task much easier. Thanks are extended to each reviewer for performing this critically important work. In addition to the members of the Editorial Board, the other reviewers for this issue include:

$\begin{array}{ll}\text { Steve L. Anderson } & \text { St. Cloud State University } \\ \text { Brent W. Balazs } & \text { Metropolitan State College of Denver } \\ \text { Ken Barnard } & \text { Kansas State University } \\ \text { John H. Cain } & \text { Florida Institute of Technology } \\ \text { David Conway } & \text { Southeastern Oklahoma State University } \\ \text { Paul A. Craig } & \text { Middle Tennessee State University } \\ \text { Richard O. Fanjoy } & \text { Purdue University } \\ \text { Ronald Ferrara } & \text { Middle Tennessee State University } \\ \text { John W. Horine } & \text { Central Missouri State University } \\ \text { Juan Merkt } & \text { Jacksonville University } \\ \text { Mary C. Niemczyk } & \text { Arizona State University } \\ \text { Donald A. Petrin } & \text { Purdue University } \\ \text { C. Daniel Prather } & \text { Middle Tennessee State University } \\ \text { Jose R. Ruiz } & \text { Southern Illinois University Carbondale } \\ \text { Teresa A. Sloan } & \text { Central Washington University } \\ \text { Guy M. Smith } & \text { Embry-Riddle Aeronautical University } \\ \text { Alan J. Stolzer } & \text { Embry-Riddle Aeronautical University } \\ \text { Henry L. Taylor } & \text { University of Illinois - Urbana/Champaign } \\ \text { Stacey Weislogel } & \text { The Ohio State University } \\ \text { John Young } & \text { Purdue University }\end{array}$




\section{STATEMENT OF OBJECTIVES}

The Collegiate Aviation Review is published semi-annually by the University Aviation Association. Papers published in this volume were selected from submissions that were subjected to a blind peer review process, for presentation at the 2011 Fall Education Conference of the Association.

The University Aviation Association is the only professional organization representing all levels of the non-engineering/technology element in collegiate aviation education. Working through its officers, trustees, committees and professional staff, the University Aviation Association plays a vital role in collegiate aviation and in the aviation industry.

The University Aviation Association accomplishes its goals through a number of objectives:

To encourage and promote the attainment of the highest standards in aviation education at the college level.

To provide a means of developing a cadre of aviation experts who make themselves available for such activities as consultation, aviation program evaluation, speaking assignments, and other professional contributions that stimulate and develop aviation education.

To furnish a national vehicle for the dissemination of knowledge relative to aviation among institutions of higher education and governmental and industrial organizations in the aviation/aerospace field.

To foster the interchange of information among institutions that offer non-engineering oriented aviation programs including business technology, transportation, and education.

To actively support aviation/aerospace-oriented teacher education with particular emphasis on the presentation of educational workshops and the development of educational materials in the aviation and aerospace fields.

\section{University Aviation Association}

3410 Skyway Drive

Auburn, AL 36830

Telephone: (334) 844-2434

Email: uaa@auburn.edu 


\section{Call for Papers}

The Collegiate Aviation Review (CAR) is the refereed journal of the University Aviation Association (UAA). Both qualitative and quantitative research manuscripts relevant to collegiate aviation are acceptable. The $C A R$ review process incorporates editorial recommendations from a panel of blind peer reviewers active in the focus area of each manuscript. A list of all reviewers is published in each edition of the $C A R$, or is available from the $C A R$ editor.

Authors should e-mail their manuscript, in Microsoft Word format, to the editor at CARjournal@uaa.aero no later than June 1 (Fall 2011 issue) or December 1 (Spring 2012 issue). Manuscripts must conform to the guidelines contained in the Publication Manual of the American Psychological Association, 6th ed. Previous editions of the CAR should also be consulted for formatting guidance. All submissions must be accompanied by a statement that the manuscript has not been previously published and is not under consideration for publication elsewhere.

If the manuscript is accepted for publication, the author(s) will be required to submit a final version of the manuscript via e-mail, in "camera-ready" Microsoft Word format, by the prescribed deadline.

All authors will be required to sign a "Transfer of Copyright and Agreement to Present" statement in which (1) the copyright to any submitted paper which is subsequently published in the $C A R$ will be assigned to the UAA and in which (2) the authors agree to present any accepted paper at a UAA conference to be selected by the UAA, if requested. Students are encouraged to submit manuscripts to the CAR. A travel stipend for conference attendance up to $\$ 500$ may be available for successful student submissions. Please contact the editor or UAA for additional information.

Questions regarding the submission or publication process may be directed to the editor at (615) 494-8755, or may be sent by email to: CARjournal@uaa.aero. 


\section{TABLE OF CONTENTS}

Impacts of Public Law 111-216: Will the Flight Instructor Career Path Remain a Viable Option for Aspiring Airline Pilots?

Elizabeth Bjerke and Daniel Malott..........................................................................1

Elements Related to Teaching Pilots Aeronautical Decision Making

Ronda E. Cassens, John P. Young, James P. Greenan, and James M. Brown..................10

The Marketability of Higher Education Aviation Graduates as Perceived by Regional Airline Pilots

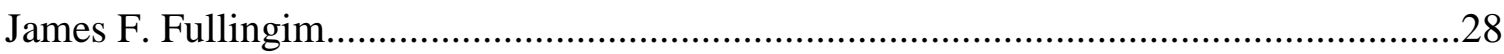

Survey of Flight Instructors' Experiences in Communication Training

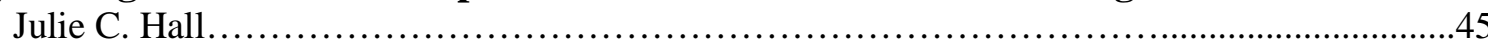




\title{
Impacts of Public Law 111-216: \\ Will the Flight Instructor Career Path Remain a Viable Option for Aspiring Airline Pilots?
}

\author{
Elizabeth Bjerke and Daniel Malott \\ University of North Dakota
}

\begin{abstract}
On August 1, 2010, President Obama signed Public Law 111-216. This new legislation impacts the practices of 14 CFR Part 121 air carriers, as well as dictating the requirement of all airline pilots to hold an Airline Transport Pilot (ATP) certificate. This study examines how a flight instructor in a 14 CFR Part 141 pilot school measures up to the aeronautical experience requirements of the ATP. Aeronautical experience of 174 current flight instructors employed by a Part 141 collegiate aviation program was analyzed. The results indicate that this group of flight instructors significantly lacked the required crosscountry flight experience required by the ATP certificate. The research also found that the number of flight instructors aspiring to work for air carriers is on the decline.
\end{abstract}

\section{INTRODUCTION}

On August 1, 2010, President Obama signed Public Law 111-216: Airline Safety and Federal Aviation Administration (FAA) Extension Act of 2010. The primary sponsor of the bill was Rep. James Oberstar of Minnesota, who introduced it to the $111^{\text {th }}$ Congress just four days prior on July 28, 2010. H.R. 5900 (2010) contains two main parts: Title I-Airport and Airway Extension and Title II-Airline Safety and Pilot Training Improvement. This research focuses on Title II and its potential impact on the nature of flight training.

Title II, Section 216, Flight Crewmember Screening and Qualifications, of the legislation includes various requirements for the hiring process of flight crewmembers. In paragraph B it states:

ALL FLIGHT CREWMEMBERS.--Rules issued under paragraph (1) shall ensure that, after the date that is 3 years after the date of enactment of this Act, all flight crewmembers-

(i) have obtained an airline transport pilot certificate under part 61 of title 14, Code of Federal Regulations; and

(ii) have appropriate multi-engine aircraft flight experience, as determined by the Administrator.

(H.R. 5900, 2010, pg. 20)

Additionally, Section 217, Airline Transport Pilot (ATP) Certification, goes on to state the following, "The Administrator of the Federal Aviation Administration shall conduct a rulemaking proceeding to amend part 61 of title 14, Code of Federal Regulations, to modify requirements for the issuance of an airline transport pilot certificate.” (H.R. 5900, 2010, pg. 20) Minimum requirements are set forth, and include various training and/or experience in a variety of settings. The bill does state that a minimum of 1,500 total flight hours will be required. In addition to these 1,500 hours, Section 217 also requires sufficient flight hours in difficult operational conditions that may be encountered by an air carrier.

The bill also includes a specific statement to allow the FAA Administrator to grant credit towards the flight hour requirements by completing certain academic courses that will enhance safety. (H.R. 5900, 2010) No specific subject matter is identified at this time. The requirement for all Part 121 flight crewmembers to have or obtain an ATP certificate will go into effect three years after the date of enactment. 


\section{REVIEW OF LITERATURE}

The aeronautical experience requirements for the ATP certificate are set forth in Part 61 of Title 14, CFR. Specifically, Part 61.159 specifies the following: 1,500 total time, including at least 500 hours of cross-country flight time, 100 hours of night flight time, and 75 hours of instrument flight time (FAR, 2010b). Table 1 includes the FAA ATP aeronautical experience requirements along with the percentage of total time breakdown for each sub-category.

The ATP requires 500 hours of cross-country time, which can account for 33\% of the overall 1,500 hour requirements. This is the largest sub-category identified for the ATP certificate. The FAR's currently define cross-country time for the ATP certificate by the following:

(vi) For the purpose of meeting the aeronautical experience requirements for an airline transport pilot certificate (except with a rotorcraft category rating), time acquired during a flight-

(A) Conducted in an appropriate aircraft;

(B) That is at least a straight-line distance of more than 50 nautical miles from the original point of departure; and

(C) That involves the use of dead reckoning, pilotage, electronic navigation aids, radio aids, or other navigation systems. (FAR, 2010a)

The International Civil Aviation Organization (ICAO) has nearly identical Airline Transport Pilot's License (ATPL) requirements with the exception of cross-country time. ICAO (2006) requires 1,500 hours total time, including at least 200 hours cross-country flight time, 100 hours night flight time, and 75 hours of instrument flight time. Table 1 outlines the ICAO ATPL flight hour requirements and the percentage of time in relation to 1,500 total hours.

Table 1. Comparison between FAA ATP and ICAO ATLP Requirements

\begin{tabular}{lllll}
\hline & FAA ATP Hours & $\begin{array}{l}\text { FAA ATP } \\
\text { Percentage of } \\
1500\end{array}$ & $\begin{array}{l}\text { ICAO ATP } \\
\text { Hours }\end{array}$ & $\begin{array}{l}\text { ICAO ATP } \\
\text { Percentage of } \\
1500\end{array}$ \\
\hline Total Time & 1500 & NA & 1500 & NA \\
Cross-Country & 500 & $33 \%$ & 200 & $13 \%$ \\
Night & 100 & $7 \%$ & 100 & $7 \%$ \\
Instrument & 75 & $5 \%$ & 75 & $5 \%$ \\
\hline
\end{tabular}

Note. Requirements from FAR, 2010 and ICAO, 2006

The largest percentage of flight time for the ICAO ATPL is also cross-country flight time, however there is a difference of 300 hours, or $20 \%$ of the 1,500 total hours between the ICAO and FAA cross country requirements. ICAO (2006) defines Cross-Country "as a flight between a point of departure and a point of arrival following a pre-planned route using standard navigation procedures." Note that ICAO does not require a minimum distance for the cross-country flight.

The requirement that all Part 121 pilots hold an ATP certificate could potentially change the supply versus demand ratio for airlines yet no research has been published in this area to analyze the effects. Prior to this new legislation, numerous forecasting studies had been conducted predicting not only a nationwide shortage of qualified pilots, but worldwide as well. 
Lovelace and Higgins (2010) reported at the FAA forecasting conference that there would be a shortage of 85,777 pilots between 2010 and 2025. This study utilized regression analysis, historical data for pilot supply, and FAA forecast data for industry demand. A discussion at the Next Generation of Aviation Professionals Symposium in March of 2010 (ICAO, 2010) revealed an expected global pilot shortage of 200,000 pilots by 2018. Especially in light of the worldwide economic downturn experienced in recent years, these numbers are impressive.

Smith, Bjerke, NewMyer, Niemczyk, and Hamilton (2010) found that approximately $73 \%$ of new hire airline pilots had a Certified Flight Instructor (CFI) certificate at the time of initial employment. While the study did not focus on duration or type of instruction, it is clear that a large portion of pilots who enter an airline career obtain some form of their experience as a flight instructor. The study also found that new airline pilots who had a CFI certificate had a higher completion rate for initial training, and required fewer extra training events when compared with pilots who did not have a CFI certificate.

Both the success and large number of CFIs at regional airlines indicate an important need for flight instructing to remain a viable career path for those aspiring to fly for a Part 121 air carrier. Feldt and Woelfel (2009) studied 179 undergraduate students to provide data regarding decisions to pursue careers based on anticipated career outcomes. This study confirmed previous research on career interest and social cognitive theory. It found agreement in four areas of career outcome expectations, including job satisfaction, job security, interesting work, and managing home and family life. The research also found that high income was one of the least important outcomes associated with potential career interest.

\section{Research Questions}

As a means to expand the knowledge on the current research being conducted on the implications of the newly adopted legislation, this study answered the following research questions:

1. How does the nature of flight time acquired as a flight instructor relate to the aeronautical experience requirements of the Airline Transport Pilot certificate?

2. What are the career aspirations of current flight instructors? Have these aspirations changed over time?

\section{METHODOLOGY}

\section{Participants}

During the fall of 2009 a survey was administered to a cadre of Certified Flight Instructors (CFI) currently employed in a large 14 CFR Part 141 collegiate aviation flight program. A total of 173 CFIs completed the survey. Nine (5\%) CFIs already held an Airline Transport Pilot (ATP) certificate, thus their records were not used for further analysis. The subjects were chosen based upon their employment in the collegiate aviation flight program. Both full-time and part-time CFIs completed the survey.

\section{Materials}

The survey was constructed by a committee of individuals who had a diverse set of subject matter expertise, including those with domain relevant experience and those with survey building experience and training. The resultant survey can be broken down in three sections. One section recorded background information including the following: age, year obtained initial CFI, pilot certificate and previous flight experience. The second section recorded current aeronautical experience (flight time) in the following categories: total time, cross-country time, instrument time and night time. The last section documented 
the career aspirations of the subject. The survey was approved by the institution's review board since it involved the questioning of human subjects.

\section{Procedures}

The researchers administered the paper survey at a flight operations meeting which all of the employed CFIs were required to attend. The CFIs were asked to bring their updated pilot logbooks to the meeting in order to answer the aeronautical experience questions accurately. Although the survey was administered at a mandatory meeting, participation was strictly voluntary. No identifying information was collected on the survey tool. Once the survey was administered the researchers inputted the results into SPSS data mining and statistical analysis software for further analysis.

\section{RESULTS}

The sample for this study consisted of certified flight instructors employed in a collegiate aviation 14 CFR Part 141 flight program. In total 173 completed surveys were obtained from the instructor group. Background information about the sample is presented in Table 2. It should be noted that all respondents that held an ATP certificate obtained their CFI certificate prior to 2004 and had a combination of flight experience besides just acting as a flight instructor.

Table 2. Background Information

\begin{tabular}{lll}
\hline Characteristics & $n$ & $\%$ \\
\hline Pilot Certificate & & \\
$\quad$ Commercial & 164 & 94.8 \\
Airline Transport Pilot & 9 & 5.2 \\
& & \\
Year obtained CFI & 15 & 8.9 \\
Prior to 2004 & 8 & 4.8 \\
2005 & 23 & 13.7 \\
2006 & 36 & 21.4 \\
2007 & 64 & 38.1 \\
2008 & 22 & 13.1 \\
2009 & & \\
& & 84.4 \\
Flight Experience & 146 & 15.6 \\
Only Flight Instruction & 27 & \\
Combination (CFI, 121, Cargo) & &
\end{tabular}

Note. $n=173$

\section{Aeronautical Experience Analysis}

As a basis for measuring aeronautical experience as it relates to the ATP certification requirements, the flight instructor respondents were asked to provide flight time data. Table 3 lists the overall means of various flight time categories that are required for the ATP certificate. The following analysis omits the flight times reported by the respondents which already hold an ATP certificate. 
Table 3. Aeronautical Experience

\begin{tabular}{lll}
\hline Aeronautical Experience & Mean & Standard Deviation \\
\hline Total Flight Time & 862.8 & 491.3 \\
Total Cross-Country Time & 218.1 & 163.9 \\
Total Instrument Time & 86.7 & 64.0 \\
Total Night Time & 110.4 & 76.9 \\
\hline
\end{tabular}

Note. $n=161$

The respondents were also asked to report the flight time acquired in the last 12 months. The instructors indicating that they worked as a flight instructor full-time for the last 12 months acquired a mean total time of 446.2 hours $(n=82)$, and mean total cross-country time of $110.5(n=82)$.

In order to compare the aeronautical experience acquired by flight instructing to the ATP requirements, percentages were calculated comparing the flight time received in various categories to total time obtained by the respondent. Table 4 states the comparison of these percentages. The sampling of flight instructors in this group exceeds the percentage required for both night and instrument flying, however significantly lacks the percentage of cross country time required by the ATP certificate.

Nearly $12 \%$ ( $n=17)$ of the flight instructors responding to this survey indicated that they had received aeronautical experience outside of flight instructing. Thus a $t$-test was performed to analyze the difference between cross-country percentages of those solely acting as flight instructors and those gaining aeronautical experience in a variety of means (previous airline experience, cargo flying, charter flying, etc.). A significant difference was found indicating that those pilots who obtained experience outside of flight instructing acquired higher cross-country percentages than those who worked only as flight instructors $(t[159]=-2.907, p=0.004)$.

Table 4. Aeronautical Experience Percentages compared to ATP Requirements

\begin{tabular}{lcc}
\hline Aeronautical Experience & CFI Sample & ATP Requirements \\
Percentages of Total Time & & $33 \%$ \\
\hline Cross-Country & $24.7 \%$ & $7 \%$ \\
Instrument & $11.5 \%$ & $5 \%$ \\
Night & $13.0 \%$ & \\
\hline
\end{tabular}

\section{Career Aspiration Analysis}

The second aspect of this research study aimed to discover the current career aspirations of flight instructors and see if these aspirations had changed over time. In order to gather data on this topic a series of questions were asked. The first question asked "What were your career aspirations when you began your flight training?” The second question asked "Have your career aspirations changed?” Lastly, it was asked "If your career aspirations changed, what is your current career aspiration?" The frequency and percentage results of the first and last question are depicted on Table 5. 
Table 5. Career Aspirations, Original versus Current

\begin{tabular}{lcccc}
\hline \multicolumn{1}{c}{ Career } & Original & Original & Current & Current \\
& $\mathrm{N}$ & $\%$ & $\mathrm{~N}$ & $\%$ \\
\hline Airline Pilot & 97 & $56 \%$ & 41 & $24 \%$ \\
Corporate Pilot & 28 & $16 \%$ & 29 & $17 \%$ \\
Military Pilot & 5 & $3 \%$ & 7 & $4 \%$ \\
Professional CFI & 1 & $1 \%$ & 4 & $2 \%$ \\
Other & 8 & $5 \%$ & 55 & $32 \%$ \\
Combination & 22 & $13 \%$ & 23 & $13 \%$ \\
Missing Data & 13 & $8 \%$ & 15 & $9 \%$ \\
\hline
\end{tabular}

Note. $N=174$

A Chi-Square test of significance compared those indicating a change in career aspirations between those initially indicating an airline career to all other careers $\left(\chi^{2}[1, n=161]=6.985, p=0.008\right)$. In Table 6 , the results show that flight instructors initially aspiring to be airline pilots changed their career aspirations more than those who originally aspired to enter into other pilot professions.

Table 6. Chi-Square Comparison between Original Career Aspirations and Change that Occurred

\begin{tabular}{llcc}
\hline Original Career Aspirations & & Change (Yes) & Change (No) \\
\hline Airline Pilot & Observed/Expected & $60 / 51.8$ & $37 / 45.2$ \\
& $\chi^{2}$ Contribution & $37 \%$ & $23 \%$ \\
Other (Corporate, Military, CFI) & Observed/Expected & $26 / 34.2$ & $38 / 29.8$ \\
& $\chi^{2}$ Contribution & $16 \%$ & $24 \%$ \\
\hline
\end{tabular}

\section{DISCUSSION AND CONCLUSION}

This study aimed to answer two distinctive research questions in regards to how the recent passing of Public Law 111-216 could ultimately impact the typical career progression of aspiring airline pilots, which often includes gaining aeronautical experience as a flight instructor. The first question focused on the aeronautical experience requirements of the ATP certificate, and how time acquired as a flight instructor would serve to meet the hourly requirements.

The results of this research indicate that flight instructors are at a disadvantage when it comes to gaining the required aeronautical experience required for the FAA ATP certificate, namely in the category of cross-country time. In order to better illustrate this disadvantage, take for example a newly hired flight instructor and assume that he/she is beginning this step in his/her career with the minimum hours that a commercial pilot would have to obtain (250 hours of total flight time, 50 hours of cross-country time). The research results indicated that a full-time flight instructor in this particular Part 141 collegiate aviation program obtained on average 446 total flight hours per year, of these 110 were also classified as cross-country time. It would take this individual approximately 2.8 years to obtain the needed flight hours to meet the FAA ATP requirement of 1,500 hours of total time. However, it would take this same individual an additional 1.3 years, or a total of 4.1 years to meet the 500 hours of cross-country currently required for the FAA ATP certificate. This would not be the case in meeting the ICAO ATP requirement 
of only 200 hours of cross-country time. The ICAO ATP cross-country time could be met in only 1.4 years.

To better understand the make-up of flight time requirements in the flight training environment, an analysis was conducted utilizing the training course requirements specified by the Part 141 approved curriculum. Table 7 includes total dual (instructional) flight time, dual cross-country flight time, and solo cross-country flight time.

Table 7. Training Course Requirements of Part 141 College Curriculum

\begin{tabular}{lccccc}
\hline & Private & Commercial & CFI & CFII & Total \\
\hline Total Dual Instruction & 27 & 68 & 25 & 15 & 135 \\
Dual Cross-Country & 3 & 16 & 0 & 0 & 19 \\
Solo Cross-Country & 3 & 14 & 0 & 0 & 17 \\
\hline
\end{tabular}

The 19 hours of minimum dual cross-country flight time represents $14 \%$ of the 135 hours of total dual a CFI would expect for a single student through the entire collegiate curriculum. This is a reflection of minimum hours, and does not factor in repeat cross-country lessons, or conducting cross-country flight that exceed the minimum time requirement. Although the percentage of cross-country time per total dual instruction time is nearly $20 \%$ less than needed by the FAA ATP criteria, it would be sufficient in obtaining the ICAO ATPL cross-country requirement.

Under the direction of H.R. 5900 (2010), the FAA administrator has already been tasked with looking into the FAA ATP requirements. Section 217 of H.R. 5900 (2010) states:

(a) Rulemaking Proceeding- The Administrator of the Federal Aviation Administration shall conduct a rulemaking proceeding to amend part 61 of title 14, Code of Federal Regulations, to modify requirements for the issuance of an airline transport pilot certificate. (pg. 20)

It is strongly recommended that the administrator, along with the rule making committee, seriously analyzes the current requirement of 500 hours of cross-country time for the ATP certificate, along with the current definition of cross-country time for aeronautical experience prescribed for the ATP requirement. Neither the hourly requirement nor the definition is currently in line with the ICAO requirement or definition for cross-country requirements. By reducing the cross-country aeronautical experience requirement for the ATP, flight instructors could more readily meet the ATP aeronautical experience requirements.

Due to the current make up of aeronautical experience required for the FAA ATP, flight instruction does not prove to be the most efficient means by which to gain the needed flight time in relation to crosscountry experience. The results of this study indicated a significant difference between pilots who have obtained their flight time by solely flight instructing, versus those who have obtained flight time by a variety of means versus their cross-country percentage in relation to total time. The impact of requiring all Part 121 airline pilots to hold an ATP certificate may negatively affect the decision of well qualified pilots seeking employment as a flight instructor. If it is realized that it is more difficult to obtain the aeronautical experience requirement of 500 hours of cross-country time as a flight instructor, many of these qualified individuals may opt to find employment in other flight related careers. This could leave a shortage of qualified flight instructors to teach the future generation of pilots. 
In order to gain the aeronautical experience required for the FAA ATP, flight instructors and flight programs alike may opt to re-examine how they structure their current flight courses. Many may try to place more required dual cross-country lessons into the curriculum. While this may have a positive impact on student learning, it is bound to have a negative impact on the financial burden placed on flight students. Future research needs to be accomplished to analyze the unintended impact that this legislation may have on the cost of flight training for all pilots.

The second part of this research aimed to analyze how the long-term career aspirations of a current set of flight instructors could be impacted by the passing of Public Law 111-216. It is evident that the career aspiration of becoming a Part 121 airline pilot is diminishing. Over half of the sample surveyed indicated that they originally aspired to be airline pilots, while currently less than a quarter still hope to pursue that route. This could have significant ramifications for the airline industry as a whole, especially with an impending pilot shortage on the horizon. More research needs to be conducted in order to assess exactly why this change in career aspirations is occurring in this population of flight instructors.

This research study was accomplished at a Part 141 collegiate flight training program. Additional research needs to be conducted with other groups of flight instructors, especially those providing flight training in a Part 61 environment to see if the same results are found. This study should also be replicated at other Part 141 flight schools in order to verify the results.

As the FAA moves forward in enacting the requirements spelled out in Public Law 111-216, it is imperative that research is conducted to help analyze and predict what impacts may occur. While all of the sections outlined in Public Law 111-216 directly affect the Part 121 carriers, many of the sections will have trickle down effects in other aspects of the aviation community. These effects need to be identified and evaluated before negative ramifications take place within the general aviation community. 


\section{REFERENCES}

Airline Safety and Federal Aviation Administration Act of 2010, Pub. L. No. 111-216, 123 Stat. 201 (2010).

Federal Aviation Regulations, 14 C.F.R. § 61.1 (2010a).

Federal Aviation Regulations, 14 C.F.R. § 61.159 (2010b).

Feldt, R. \& Woelfel, C. (2009). Five factor personality domains, self-efficacy, career-outcome expectations, and career indecision. College Student Journal, 43(2), 429-437.

International Civil Aviation Organization. (2010, August). Addressing the future of competent aviation professionals (No. A37-WP/86). Montreal, Canada: Author.

International Civil Aviation Organization. (2006, July). Annex 1 to the convention on international civil aviation: Personnel licensing. Montreal, Canada: Author.

Lovelace, K. \& Higgins, J. (2010, March). U.S. Pilot Labor Supply [PowerPoint Slides]. Presented at the $35^{\text {th }}$ Annual FAA Aviation Forecast Conference, Washington, D.C. Retrieved from http://www.faa.gov/news/conferences_events/aviation_ forecast_2010/agenda/media/GAF\%20Jim\%20Higgins\%20and\%20Kent\%20Love.pdf

Smith, G., Bjerke, E., NewMyer, D., Niemczyk, M., \& Hamilton, R. (2010). Pilot source study: An analysis of pilot backgrounds and subsequent success in US regional airline training programs. International Journal of Applied Aviation Studies, 10(1), 73-96. 


\title{
Elements Related to Teaching Pilots Aeronautical Decision Making
}

\author{
Ronda E. Cassens, John P. Young, and James P. Greenan
}

Purdue University

James M. Brown

University of Minnesota

\begin{abstract}
The Federal Aviation Administration (FAA) has placed increasing emphasis on aeronautical decision making (ADM) instruction, and it is critical that flight training schools ensure that their students are meeting and exceeding these requirements, especially since it has been shown that training in ADM can reduce the amount of errors caused by poor decision making (Berlin et al., 1982; Buch \& Diehl, 1984; Buch, Lawton, \& Livack, 1987; Connolly \& Blackwell, 1989; Telfer, 1989). The goal of this study was to determine the status of ADM training at a collegiate flight training school and if there was any need for program improvement. Two surveys were used to define the ADM training environment. One survey was designed to determine the methods that professors believe should be used to teach ADM and the elements of ADM that should be included in instruction. A second survey focused on identifying methods and elements that were currently being used by flight instructors. The results of the surveys were then compared to determine if there were significant differences between what professors of aviation believed should be taught and what flight instructors were actually teaching in regards to ADM. The findings suggest that instructors were not consistently using the types of situations that allow students to practice decision making, nor were they consistently emphasizing the different types of elements that contribute to good decision making. Recommendations based on this research included: (a) analyzing the nature of ADM-related instruction at other collegiate flight training schools using similar methodology, (b) providing additional ADM-related ground and flight instruction, (c) determining the students' perceptions of ADM instruction in the aircraft, and (d) adapting lesson plans to provide additional/more effective opportunities for students to practice ADM.
\end{abstract}

\section{INTRODUCTION}

\section{Elements Related to Teaching Pilots Aeronautical Decision Making}

Decision-related errors account for $71 \%$ of fatal accidents caused by the pilot (Aircraft Owners and Pilots Association, 2009). The Federal Aviation Administration (FAA) has begun to place more emphasis on decision making in order to help reduce the occurrence of these accidents. Its most recent program focuses on technically advanced aircraft (TAA) and is called the FAA Industry Training Standards, or FITS. This program uses scenario-based training (SBT) that goes beyond training a pilot to pass the practical test to enhance a pilot's aeronautical decision making, risk management, and single-pilot resource management skills (FAA, 2009). With this greater emphasis on ADM, it is important to ensure that students in flight training programs are receiving the skills they need to become better decision makers through continuous program evaluation and revision. Therefore, the survey that was created for this study focused on two areas, methods of ADM instruction and elements that may be incorporated in instruction.

\section{Review of the Literature}

Jensen and Benel (1977) completed the first comprehensive study of general aviation pilot judgment 
for the FAA. They found that the majority of general aviation accidents were caused by judgment errors and suggested that training programs should be developed to teach pilots good judgment, instead of simply relying on experience. Several suggestions were also made for developing programs. The recommendations that were developed from this study were revolutionary; previously, traditional flight instruction had focused on flying skills and aeronautical knowledge rather than judgment training (Jensen, 1995). Subsequent research determined that training in judgment and decision making effectively reduces the number of judgment errors that pilots make (Berlin et al., 1982; Buch \& Diehl, 1984; Buch, Lawton, \& Livack, 1987; Connolly \& Blackwell, 1989; Telfer, 1989). In short, good decision making can be taught and ADM instruction is effective. Unfortunately, many flight training programs are still utilizing traditional instructional methods, which leave little opportunity for the student to practice ADM skills.

\section{ADM Instructional Methods}

The best way to teach ADM is to introduce the basic concepts of decision making, place the student in situations where he or she can practice ADM, and positively reinforce safe judgment and decision making behaviors (FAA, 1991). There are two tools that pilots need to develop through practice to help build their ADM skills: cognitive strategies and problem solving tactics (FAA, 2008). Cognitive strategies focus on the "how" instead of knowing facts. As experience is gained, a pilot will develop strategies to deal with commonly encountered problems, providing a basis for making decisions. Problem solving tactics involve noticing a frequent type of error, and then developing methods to reduce that error. If a student makes an error during instruction, the instructor should ask the student to evaluate why the error occurred and to suggest ways to prevent it from happening again. The student should also actively identify errors, be aware of situations where an error is most likely to occur, and use standard routines and checklists to catch errors before they happen (FAA, 2008).

Another training method that emphasizes allowing a student to practice his or her judgment skills was presented by Brecke (1981). He defined judgment as "making more or less educated guesses if one does not know everything one should know in a given situation” (p. 147). As such, each training flight should include varying levels of uncertainty, as well as elements of cognitive complexity, time constraints, and stress. Judgment is more difficult to perform when there is less information, which introduces an element of uncertainty. Tasks that are more cognitively complex include several possible options. It is also more difficult to exercise judgment when there is less time to perform a task. Lastly, stress can be introduced by establishing a conflict between a flight problem and a background problem. The background problem involves things that are unrelated to the flight that can affect the outcome, such as the need to get to an important business meeting. It is essential that students distinguish between the two in order to consistently exercise good judgment. Stress can also be caused by the flight problem itself (Brecke, 1981).

Machado (2009) offered a very simple way of teaching ADM: observation. Students are usually not aware of all the decisions that an instructor is making throughout a flight; therefore, it is important for instructors to verbally share their thought processes with students. The student can then perceive how a

pilot with experience makes decisions and emulate the process. Additional suggestions for reducing the number of general aviation accidents were presented by the Joint Safety Analysis Team (2002). After examining 30 accidents they identified the decisional errors that contributed to each occurrence, and then an expert panel produced a list of recommended interventions. Some of these interventions included training to recognize in-flight hazards and their countermeasures, use of decision points to assess and revise the flight if necessary, retaining multiple options in case the flight does not proceed as planned, use of checklists, periodic assessment of the flight status (e.g., fuel, weather, fatigue, stress), use of other pilots' experiences to learn about good and bad decisions, and using the Personal Minimums Checklist developed by the FAA ( n.d.). 
Nine methods to improve ADM instruction were derived based on the suggestions presented by previous research and variety of initiatives (Brecke 1981; FAA, 2008; Joint Safety Analysis Team, 2002; Machado, 2009). They include:

1. Specifically evaluating students for their ability to exercise good Aeronautical Decision Making.

2. Allowing students to make go/no go decisions for every flight and evaluate those decisions.

3. Placing students in situations that encourage them to use good Aeronautical Decision Making procedures.

4. Introducing complex problems with time constraints and stress during flight training.

5. After a lesson, reviewing the poor decisions that were made during the flight and ways to correct them with students.

6. Encouraging students to look for judgment errors during flight.

7. Explaining decision making process during flight so students can learn by example.

8. Setting a good example of Aeronautical Decision Making for students.

9. Incorporating realistic scenarios into lessons to develop decision making skills (Cassens, 2010).

\section{Models of ADM and their Elements}

Over time, many different methods and models have been developed to teach ADM. Two different categories of models were examined in this research: classical and naturalistic. Classical models are characterized by linear, step-by-step decision making. Naturalistic models are non-linear and are modeled after how experts make decisions. The literature review covered nine various decision making models: conventional (FAA, 1991), FAA (FAA, 2008), Jensen's judgment (Jensen, 1995), drawing a box (Wright, n.d.), setting decision points (Belanger, 2001), AOPA (Peterson, 2006), SA and CoA (Orasanu \& Fischer, 1997), ADM expertise (Kochan, Jensen, Chubb, \& Hunter, 1997), and cognitive SOARing (Adams, 1994). The first six models fit into classical decision making, while the last three models use naturalistic theories.

The conventional model (FAA, 1991) is the most basic, and consists of the pilot noticing that a change has occurred that requires a decision to obtain the desired result. Then the possible responses are evaluated, and a best course of action is selected. If the change goes undetected and if the pilot's mental skills or piloting skills are lacking, an accident can result. The FAA has expanded on this simple model for use in aviation, and the following is a summary of the documents the FAA has produced in the past years.

The FAA (1991) published Advisory Circular 60-22, which listed the following steps for good decision making:

1. Identifying hazardous attitudes that can affect the safety of the flight

2. Learning how to modify behavior

3. Learning stress recognition and coping techniques

4. Developing risk assessment skills

5. Using all available resources in a multi-crew environment

6. Evaluating the effectiveness of one's ADM skills

Steps one and two involve recognizing the hazardous attitudes (antiauthority, impulsivity, invulnerability, macho, and resignation), and using their antidotes (follow the rules, think first, it could happen to me, it's foolish to take chances, and I can make a difference) to avoid having an accident. It is also important to recognize the negative impact of stress on decision making since great amounts of stress 
can decrease performance (Diehl, Hwoschinsky, Livack, \& Lawton, 1987; FAA, 1991). Risk management involves evaluating four risk areas, the pilot, the aircraft, the environment, and external pressures (PAVE). The next step is to use all of the available resources in a crew environment; however, a person who operates as a single pilot also has resources available. In single-pilot resource management (SRM), the pilot must manage resources both inside and outside the aircraft to gather and analyze information, and make decisions based on that information. Lastly, evaluating the effectiveness of one's decision making skills involves continuously monitoring the situation to ensure that the desired outcome is being achieved. One process that can be used for this purpose is the DECIDE model: (a) Detect that a change has occurred, (b) Estimate the need to react to the change, (c) Choose a desired outcome, (d) Identify actions that can control the change, (e) Do the action that will affect the change, and (f) Evaluate the effect of the action (Diehl, et al., 1987; Federal Aviation Administration, 1991, 2003).

Jensen's judgment model (1995) defined several basic abilities needed for decision making: observation, perception, curiosity, information processing, knowledge, problem solving, creativity, computation, mental fortitude, discipline, leadership, and people skills. These basic abilities are crucial to his judgment model, which includes eight steps: problem vigil, recognition, diagnosis, alternative identification, risk assessment, background factor, decision making, and action. Problem vigil involves actively searching for changes in the flight environment. Then the pilot must be able to recognize that a change could endanger the flight and diagnose the nature of the problem. Next, the pilot examines all the alternatives that would solve the problem based on knowledge of the aircraft, environment, and aviation system. These alternatives are then evaluated for their associated risks. The background factor consists of the outside influences that add bias to the entire decision making process, but has the most impact immediately before the decision is made. These influences affect the pilot's ability to make a rational decision and can include the need to arrive at the destination, pressure from the passengers, and pride. The final steps include choosing an alternative and carrying out the action.

The drawing a box model consists of breaking a large task into smaller pieces and presenting them in a logical manner that is useful for the student. Wright (n.d.) suggested a three step process:

1. Know and operate within one's capabilities.

2. Examine a given situation, evaluate current skills, and set boundaries for that situation. In other words, create a box of operating parameters.

3. Always operate within the box.

These steps must be completed before the flight begins since being in a critical situation could cause the pilot to make a rash decision. Each pilot's box will be different and will change with experience. It is also suggested that instead of thinking of ADM as Aeronautical Decision Making, it should be thought of as "Applied Decision Making." This new meaning would help encourage instructors to give students the opportunity to practice decision making during training to apply what they have learned.

The setting decision points model is based on the fact that pilot-caused accidents stem from a poor decision that was made at some point (Belanger, 2001). There are five areas discussed: hazardous attitudes, random risks, amount and type of information available, setting, and decision points. Belanger expanded on the FAA's hazardous attitudes concept by pairing the five traits with their opposites, which can be just as dangerous. Macho is paired with delicate, anti-authority is paired with unquestioning, invulnerability is paired with fearful, and resignation and impulsiveness are paired together. It is essential to operate in the middle of each spectrum. It is also important to understand the effects of random risk. Repeatedly doing something dangerous and not experiencing consequences does not make that activity safer, and each time a risk is taken, the chance of failure increases. A pilot must gather as much information as feasible to make a good decision, but not so much that he or she becomes overwhelmed. The setting in which a decision takes place can also cause a pilot to make a poor decision. Pilots should 
also make a conscious effort to make decisions, and Belanger identified several decision points, including: before going to the airport, before takeoff, enroute, and before landing.

The AOPA Air Safety Foundation (Peterson, 2006) offered a more practical method of decision making, where ADM is “doing the right thing, at the right time" (p. 1). The AOPA method describes the process used before, during, and after a flight to ensure that good decisions are made. Before the flight, the pilot should conduct a very thorough examination of all available information while still on the ground. During the flight, the pilot should enter a continuous decision making cycle, where information that the pilot already possesses (prior knowledge and knowledge gained during the preflight) is combined with the information gained during flight. The decision making process consists of three steps: anticipate, recognize, and act. After the flight is completed, the pilot should evaluate the decisions made during the flight. Things that went well and went poorly should be examined to determine if any improvements can be made, such as noticing problems sooner or taking a different action. The pilot is then better able to handle similar situations if they should occur again.

The previous models were all examples of classical decision making. The following models reflect a more naturalistic approach to decision making. Naturalistic decision making examines situations that have ill-structured problems; incomplete, ambiguous, or changing information; ill-defined, shifting, or competing goals; decisions that occur in multiple event-feedback loops; limited time available; high stakes; multiple players in the decision making process; and the need to balance personal choice with organizational norms and goals (Orasanu \& Connolly, 1993). Decision making in the aviation environment often reflects these characteristics.

The situation assessment and course of action model developed by Orasanu and Fischer (1997) was based on naturalistic decision making concepts and consisted of two main phases: situation assessment (SA) and selecting a course of action (CoA). Situation assessment involves problem definition, risk assessment of the problem, and time available to solve the problem. The next step is to choose a course of action from the available options. There are three option structures available to the pilot: rule-based, choice, and creative. A rule-based option has only one response to the particular situation that should be readily recognized by someone with expertise in the situation. A choice decision has multiple options that are based on prevailing goals and constraints. In situations where there are no suitable options available, the pilot must create his or her own options.

To help pilots become experts and exercise good judgment, they must be able to think like an expert, which is the foundation of the $A D M$ expertise model. Instead of focusing on changing the attitudes of pilots, Kochan, Jensen, Chubb, and Hunter (1997) concentrated on discovering how expert pilots think. They believed that previous approaches to ADM training had reached their maximum effectiveness due to the fact that errors in judgment are still the major cause of aviation accidents. A new cognitive model was developed to aid in training pilots to become expert pilots. The components of the model included experience (number of hours, variety, meaningfulness, relevance, and recency), risk management, problem solving, and attentional control (awareness of one's surroundings and the ability to ignore nonflight related issues).

The final model that addressed the way expert pilots think is Cognitive SOARing (Adams, 1994), which stands for Sensing, Organizing, Analyzing, and Responding to a situation. Cognitive SOARing focuses on preparation and execution, and the first preparation step in decision making is sensing changes in the environment. The next step in this process is organizing, which involves sorting, prioritizing, and structuring the information that is being sensed. The most important information is identified and used to develop an understanding of the situation or problem. Analyzing refers to the processing and evaluation of the information. The effectiveness of the pilot relies on the type of knowledge that is stored and his or her ability to retrieve that knowledge. Experts can intuitively respond to patterns without having to 
disassemble them into components. Lastly, responding consists of taking an action to change or control the situation and evaluating its effectiveness using conceptual and procedural knowledge (Adams, 1994).

The main elements of each model were compiled into a list of 22 diverse aspects with definitions and descriptions in literature by Bowman (1993) and Abner (2006):

1. change recognition

2. attitude management

3. headwork

4. course of action development

5. course of action analysis

6. course of action selection

7. risk management

8. situational awareness

9. skills and procedures

10. aviation experience

11. stress management

12. situation assessment

13. attention control

14. values

15. computing time available

16. communication

17. leadership

18. organizational influence

19. social influence

20. personality

21. dynamic problem solving

22. the poor judgment chain

\section{Purpose of the Study}

The most recent analysis of progress toward implementing ADM instruction in the collegiate flight training environment was conducted by Bowman (1993). His study focused on determining the extent to which postsecondary flight training institutions had implemented training in ADM and judgment into their curricula. This was accomplished using survey instruments. He found that $32.8 \%$ of the respondent institutions did not teach at least one of the pilot judgment and decision making curricular topics, $47.5 \%$ of the respondent institutions did not use a textbook that included pilot judgment and decision making in its content, and $29.5 \%$ of the CFI respondents had received formal training in ADM. Since it has been some time since Bowman's research, and due to the FAA's increasing emphasis on ADM training, the purpose of this research was to obtain a single point in time description of ADM instruction at a Midwestern flight training university by identifying the essential elements of ADM flight instruction and the extent to which they were being taught in that collegiate flight program. This research also sought to compare and contrast how ADM should be taught and how it was actually being taught in the targeted collegiate flight program. It was limited to one-on-one instruction in the aircraft. The study did not evaluate classroom instruction, curriculum, textbooks, or classroom materials. The research questions that were posited for this research included:

1. Which elements of ADM are important in flight instruction?

2. Which elements of ADM are being taught in flight instruction?

3. Is there is a difference between the ADM elements that should be taught and the ADM elements 
that are being taught?

4. Which instructional methods should be used to teach ADM?

5. Which instructional methods are being used to teach ADM?

6. Is there a difference between the instructional methods that should be used to teach ADM and the instructional methods that are being used to teach ADM?

Surveys of aviation professors (experts) were used to identify key components of the educational environment that should exist and surveys of flight instructors focused on how flight training is delivered at the targeted flight training institution. The surveys also revealed areas that may require program improvement.

\section{METHOD}

\section{Participants}

The population for this study was the faculty, specifically professors, associate professors, assistant professors, clinical professors, and senior aviation continuing lecturers in a collegiate flight training school. Because of the small number of available participants, all 13 of the certified flight instructors (CFIs) and aviation flight faculty who were employed by the university received surveys. Seven of the 13 faculty completed the survey. All faculty members were experts in the field of aviation flight with between 5000-10,000 hours of flight time, including four who were FAA Designated Pilot Examiners (DPEs). The faculty sample served as a panel of experts in the decision making skills that are needed to be successful in aviation. They determined the essential elements of ADM and how they should be taught. Of the seven professor respondents, one (14\%) was female. Five (71\%) of the respondents were professors at the university, and the remaining two (29\%) held full-time flight instructor positions at the university. All had a CFI license with a multi-engine instructor rating, and five were licensed ground instructors. Table 1 presents the age, total flight time, and flight instruction given for the professor sample. The subjects in the sample had a considerable amount of combined experience.

Table 1. Demographic Information for the Professor Sample

\begin{tabular}{ll}
\hline Category & N (\%) \\
\hline Age & $1(14 \%)$ \\
$18-25$ & $0(0 \%)$ \\
$26-34$ & $2(29 \%)$ \\
$35-54$ & $4(57 \%)$ \\
$55-64$ & \\
Total Flight Time (hours) & $1(14 \%)$ \\
$501-1000$ & $0(0 \%)$ \\
$1001-5000$ & $3(43 \%)$ \\
$5001-10,000$ & $3(43 \%)$ \\
$10,000+$ & $1(14 \%)$ \\
Hours of Dual Instruction Given & $2(29 \%)$ \\
$501-1000$ & $3(43 \%)$ \\
$1001-5000$ & $1(14 \%)$ \\
$5001-10,000$ & \\
$10,000+$ &
\end{tabular}

The instructor population included collegiate certified flight instructors (CFIs), which was comprised of junior aviation continuing lecturers and part-time instructors who were currently delivering flight 
instruction. The part-time CFIs were college students generally between the ages of 18 and 22. They typically had very little flight experience and flight instruction given. The junior aviation continuing lecturer CFIs were similar to the part-time instructors, with slightly more experience and some advanced instructor ratings. Three of the respondents (13\%) were female. There were 19 (83\%) instructors who were part-time instructors, and four (17\%) were junior aviation continuing lecturers. Of the 23 CFIs, seven (30\%) had obtained their instrument instructor's rating, three (13\%) had their multi-engine instructor rating, and three (13\%) had their ground instructor's license. The age, total flight time, and instruction given for the instructor sample are presented in Table 2. The instructor sample generally had significantly less total flight experience and had given fewer hours of dual instruction than the professor sample.

Table 2. Demographic Information for the Instructor Sample

\begin{tabular}{ll}
\hline Category & N (\%) \\
\hline Age & $22(96 \%)$ \\
$18-25$ & $1(4 \%)$ \\
$26-34$ & \\
Total Flight Time (hours) & $19(83 \%)$ \\
$201-500$ & $0(0 \%)$ \\
$501-1000$ & $4(17 \%)$ \\
$1001-5000$ & \\
Hours of Dual Instruction Given & $19(83 \%)$ \\
$0-200$ & $0(0 \%)$ \\
$201-500$ & $3(13 \%)$ \\
$501-1000$ & $1(4 \%)$ \\
$1001-5000$ &
\end{tabular}

\section{Research Design}

According to Gall, Gall, and Borg (2007), “descriptive research is a type of quantitative research that involves making careful descriptions of educational phenomena” (p. 300). This study obtained a single point in time description of what should be occurring in ADM training and what is actually occurring. Without an accurate description of the current status of the flight training program, program improvements cannot be identified. This study collected and analyzed data that were primarily quantitative through the use of two surveys: one for the expert faculty group and one for the flight instructor group. The surveys were nearly identical except for a few changes in the wording of the instructions to reflect what should be taught for the faculty survey and what is actually being taught for the flight instructor survey. The surveys were comprised of sections from two previously developed surveys. The first survey, created by Abner (2006), was designed to determine the essential elements of ADM in postsecondary training environments. He reviewed various ADM models and found 21 different elements that were present in these models. The second survey was developed by Bowman (1993) to ascertain whether or not ADM training had been implemented in collegiate aviation flight training programs. Portions of these two surveys were used to create the surveys that were used in this study, along with basic demographic information. A section concerning ADM instructional methods was created based on those found in the literature review.

\section{Instrumentation}

Of the 13 faculty members who received the professor survey, seven completed it, for a response rate 
of 54\%. The instructor survey was sent to 53 instructors, of which 30 instructors began the survey, for a response rate of $57 \%$. Cronbach's coefficient alpha was calculated for each scale and the total instrument to determine the internal reliability. Coefficient alpha for Part I included all the respondents. Part II of the instructor survey was calculated using only the data provided by the 23 respondents who completed the entire section. The reliability coefficients are presented in Table 3.

Table 3. Reliability Coefficients for the Professor and Instructor Survey Instruments

\begin{tabular}{lccc}
\hline Measure & $\begin{array}{c}\text { No. of } \\
\text { Items }\end{array}$ & $\begin{array}{c}\text { No. of } \\
\text { Respondents }\end{array}$ & $\begin{array}{c}\text { Cronbach's } \\
\text { Alpha }\end{array}$ \\
\hline Professor Survey & 31 & 7 & .88 \\
Part I: ADM Instructional Methods & 9 & 7 & .44 \\
Part II: ADM Elements & 22 & 7 & .86 \\
Instructor Survey & 31 & 23 & .91 \\
Part I: ADM Instructional Methods & 9 & 30 & .80 \\
Part II: ADM Elements & 22 & 23 & .87 \\
\hline
\end{tabular}

According to Nunnally and Bernstein (1994), an alpha between .70 and .80 is adequate for newly developed instruments and basic research. The Cronbach's coefficient alphas for all of the scales were .80 or higher except for Part I of the professor survey. It was very low, most likely because there was a small number of respondents and instrument items (Nunnally \& Bernstein, 1994). The total instrument and individual scales were considered to possess an adequate degree of internal consistency reliability, indicating that it would be a useful instrument for use in evaluating other flight training programs.

\section{Data Analysis}

Two identical surveys were created by the researchers based on the review of literature. These surveys included 22 elements from nine different decision making models and nine ADM instructional methods. All elements and instructional methods included a detailed definition of the item as well as an example, if necessary (Cassens, 2010). The surveys used a standard Likert-type scale: 1 = Strongly Disagree, $2=$ Disagree, 3 = Neutral, $4=$ Agree, and $5=$ Strongly Agree. Means, standard deviations, and variances were calculated for each of the professor and instructor responses. The means were used to calculate a two-tailed p-value through an unpaired t-test, which was then used to determine if there was a significant difference $(p<.05)$ between the instructor responses and the professor responses. The open-ended questions were analyzed using cross case analysis.

\section{RESULTS}

\section{Research Question 1: Which elements of ADM are important in flight instruction?}

The results from Part II of the professor survey indicated that the faculty deemed all elements to be important to ADM instruction (see Table 4). The faculty members were unanimous with respect to the flight instructor's role in emphasizing risk management during flight training. Risk management involves correctly and analytically assessing risk as opposed to assuming risk based on previous successful situational experiences (Abner, 2006; Bowman, 1993). Once areas of high risk are identified, the pilot can take the steps to reduce risk and ensure the safety of the flight. Ignoring the risks involved could lead to an accident (FAA, 2008); therefore, it was viewed as very important by the faculty. The means of the other elements ranged from 4.00 to 4.86; accordingly, virtually all elements were deemed as ones that flight instructors should be including in flight instruction. 
Table 4. Professor Ranking of ADM Elements to Incorporate into Flight Training

\begin{tabular}{lccc}
\hline Element & $\mathrm{M}$ & $\mathrm{SD}$ & Variance \\
\hline 1. Risk management & 5.00 & 0.00 & 0.00 \\
2. Course of action analysis & 4.86 & 0.38 & .14 \\
3. Course of action selection & 4.86 & 0.38 & .14 \\
4. Situational awareness & 4.86 & 0.38 & .14 \\
5. Situation assessment & 4.86 & 0.38 & .14 \\
6. Change recognition & 4.71 & 0.49 & .24 \\
7. Headwork & 4.71 & 0.49 & .24 \\
8. Course of action development & 4.71 & 0.49 & .24 \\
9. Attitude management & 4.57 & 0.53 & .29 \\
10. Skills and procedures & 4.57 & 0.53 & .29 \\
11. Stress management & 4.57 & 0.53 & .29 \\
12. Communication & 4.57 & 0.53 & .29 \\
13. Poor judgment chain & 4.57 & 0.53 & .29 \\
14. Attention control & 4.43 & 0.53 & .29 \\
15. Leadership & 4.43 & 0.53 & .29 \\
16. Organizational influence & 4.43 & 0.79 & .62 \\
17. Social influence & 4.43 & 0.79 & .62 \\
18. Dynamic problem solving & 4.43 & 0.53 & .29 \\
19. Computing time available & 4.29 & 0.49 & .24 \\
20. Aviation experience & 4.14 & 0.38 & .14 \\
21. Values & 4.00 & 0.58 & .33 \\
22. Personality & 4.00 & 1.00 & 1.00 \\
\hline
\end{tabular}

\section{Research Question 2: Which elements of ADM are being taught in flight instruction?}

In Table 5, the elements that are actually being taught by the flight instructors were determined through Part II of the instructor survey and then ranked by each element's means from highest to lowest. The flight instructors placed more emphasis on flying skills and procedures during their flight training than any other element. Although important to being able to execute a decision safely, it is a reflection of traditional instructional methods. Traditional methods often focus on mastering basic aircraft manipulation, aircraft systems knowledge, and knowledge of aviation regulations with little opportunity to practice ADM skills (Adams, 1994). The overall means of the remaining elements were lower than the faculty means, ranging from 3.65 to 4.6, indicating a lower level of use of ADM elements in general. Instructors were not incorporating these elements consistently in their flight instruction.

Table 5. Instructor Ranking of ADM Elements Used During Flight Training

\begin{tabular}{lccc}
\hline Element & M & SD & Variance \\
\hline 1. Skills and procedures & 4.60 & 0.50 & .25 \\
2. Situational awareness & 4.56 & 0.51 & .26 \\
3. Communication & 4.39 & 0.78 & .61 \\
4. Risk management & 4.36 & 0.64 & .41 \\
5. Change recognition & 4.31 & 0.79 & .62 \\
6. Leadership & 4.30 & 0.63 & .40
\end{tabular}




\begin{tabular}{llll} 
7. Aviation experience & 4.24 & 0.66 & .44 \\
8. Computing time available & 4.17 & 0.89 & .79 \\
9. Course of action analysis & 4.15 & 0.67 & .46 \\
10. Situation assessment & 4.13 & 0.74 & .55 \\
11. Organizational influence & 4.13 & 0.76 & .57 \\
12. Course of action selection & 4.12 & 0.60 & .36 \\
13. Headwork & 4.12 & 0.52 & .27 \\
14. Course of action development & 4.12 & 0.77 & .59 \\
15. Poor judgment chain & 4.09 & 0.67 & .45 \\
16. Attention control & 4.08 & 0.78 & .60 \\
17. Attitude management & 3.96 & 0.72 & .52 \\
18. Dynamic problem solving & 3.96 & 0.77 & .59 \\
19. Values & 3.79 & 0.93 & .87 \\
20. Social influence & 3.78 & 1.04 & 1.09 \\
21. Stress management & 3.67 & 0.96 & .93 \\
22. Personality & 3.65 & 0.71 & .51 \\
\hline
\end{tabular}

\section{Research Question 3: Is there a difference between the ADM elements that should be taught and the ADM elements that are being taught?}

Part II of the professor survey related to which ADM elements faculty members thought instructors should use during flight training, while Part II of the instructor survey sought to identify which ADM elements the instructors were actually using during flight training. Each element was analyzed using an unpaired t-test to determine if there was a significant difference between the means of the faculty responses and the instructor responses. Table 6 presents the statistical analysis of Part II from both surveys with reference to the item number. The degrees of freedom varied based on the number of respondents to each item. The table also lists the ranking placed on each element by each group by their respective means.

There were seven elements that had a p-value of less than .05 at the $95 \%$ confidence interval, indicating a discrepancy between what should be taught and what was actually being taught. The elements that revealed significant differences were: risk management, course of action analysis and selection, situation assessment, headwork, attitude management, and stress management. The level of instruction in these elements needed some improvement with respect to the faculty standards. 
Table 6. Part II Statistical Analysis for the Professor and Instructor Surveys

\begin{tabular}{|c|c|c|c|c|c|c|}
\hline \multirow[b]{2}{*}{ Element } & \multicolumn{2}{|c|}{ Ranking } & \multirow[b]{2}{*}{$\mathrm{t}$} & \multirow[b]{2}{*}{ df } & \multicolumn{2}{|c|}{$95 \%$ CI } \\
\hline & Prof. & Inst. & & & $\mathrm{p}$ & Sig. \\
\hline 16. Risk management & 1 & 4 & 2.67 & 31 & 0.01 & Yes \\
\hline 14. Course of action analysis & 2 & 9 & 3.07 & 30 & 0.01 & Yes \\
\hline 15. Course of action selection & 2 & 11 & 2.61 & 30 & 0.00 & Yes \\
\hline 17. Situational awareness & 2 & 2 & 1.44 & 30 & 0.16 & No \\
\hline 21. Situation assessment & 2 & 10 & 2.49 & 29 & 0.02 & Yes \\
\hline 10. Change recognition & 3 & 5 & 1.27 & 31 & 0.21 & No \\
\hline 12. Headwork & 3 & 11 & 2.69 & 31 & 0.01 & Yes \\
\hline 13. Course of action development & 3 & 11 & 1.91 & 31 & 0.07 & No \\
\hline 11. Attitude management & 4 & 14 & 2.08 & 31 & 0.04 & Yes \\
\hline 18. Skills and procedures & 4 & 1 & 0.14 & 30 & 0.89 & No \\
\hline 20. Stress management & 4 & 17 & 2.36 & 29 & 0.03 & Yes \\
\hline 25. Communication & 4 & 3 & 0.57 & 28 & 0.57 & No \\
\hline 31. Poor judgment chain & 4 & 12 & 1.73 & 28 & 0.09 & No \\
\hline 22. Attention control & 5 & 13 & 1.11 & 29 & 0.27 & No \\
\hline 26. Leadership & 5 & 6 & 0.49 & 28 & 0.63 & No \\
\hline 27. Organizational influence & 5 & 10 & 0.91 & 28 & 0.37 & No \\
\hline 28. Social influence & 5 & 16 & 1.52 & 28 & 0.14 & No \\
\hline 30. Dynamic problem solving & 5 & 14 & 1.50 & 28 & 0.14 & No \\
\hline 24. Computing time available & 6 & 8 & 0.34 & 28 & 0.73 & No \\
\hline 19. Aviation experience & 7 & 7 & 0.38 & 30 & 0.71 & No \\
\hline 23. Values & 8 & 15 & 0.56 & 29 & 0.58 & No \\
\hline 29. Personality & 8 & 18 & 1.04 & 28 & 0.31 & No \\
\hline
\end{tabular}

\section{Research Question 4: Which instructional methods should be used to teach ADM?}

Part I of the professor survey asked respondents which methods of instruction flight instructors should use during flight training. Table 7 lists the ADM instructional methods from most important to least important. The entire faculty agreed that setting a good example for students was a very important training method. Evaluating, correcting, and finding judgment errors were also high on the list. The means of the responses for all methods were between 4.57 and 5.00, indicating that the faculty members were in agreement that all of these instructional methods should be included in flight training. 
Table 7. Professor Ranking of ADM Instructional Methods by Importance

\begin{tabular}{lccc}
\hline Method & M & SD & Variance \\
\hline $\begin{array}{l}\text { 1. Set a good example of Aeronautical Decision Making for their } \\
\text { students. }\end{array}$ & 5.00 & 0.00 & 0.00 \\
$\begin{array}{l}\text { 2. Specifically evaluate students for their ability to exercise good } \\
\text { Aeronautical Decision Making. }\end{array}$ & 4.86 & .38 & .14 \\
$\begin{array}{l}\text { 3. After a lesson, review the poor decisions that were made during the } \\
\text { flight and ways to correct them with their student. }\end{array}$ & 4.86 & .38 & .14 \\
$\begin{array}{l}\text { 4. Encourage students to look for judgment errors during flight. } \\
\text { 5. Place students in situations that encourage them to use good }\end{array}$ & 4.86 & .38 & .14 \\
$\begin{array}{l}\text { Aeronautical Decision Making procedures. } \\
\text { 6. Introduce complex problems with time constraints and stress }\end{array}$ & 4.71 & .49 & .24 \\
$\begin{array}{l}\text { during flight training. } \\
\text { 7. Explain their decision making process during flight so the student } \\
\text { can learn by example. }\end{array}$ & 4.71 & .49 & .24 \\
$\begin{array}{l}\text { 8. Allow students to make go/no go decisions for every flight and } \\
\text { evaluate those decisions. }\end{array}$ & 4.57 & .53 & .24 \\
$\begin{array}{l}\text { 9. Incorporate realistic scenarios into lessons to develop decision } \\
\text { making skills. }\end{array}$ & 4.57 & .53 & .29 \\
\hline
\end{tabular}

\section{Research Question 5: Which instructional methods are being used to teach ADM?}

Part I of the instructor survey asked instructors which ADM instructional method they consistently use during flight instruction. Their responses are ranked from the most frequently used to the least frequently used in Table 8. The ADM instructional methods were somewhat similar in ranking to the Professor sample; however, the level of usage of the elements was low, with means ranging from 3.47 to 4.47 . The instructional method that was used the most by the instructors was setting a good example of decision making for students, similar to the faculty member's high ranking of this method, followed by reviewing poor decisions and ways to correct them, and evaluating students on their ADM skills.

Table 8. Instructor Ranking of ADM Instructional Methods by Level of Usage

\begin{tabular}{lccc}
\hline Method & M & SD & Variance \\
\hline $\begin{array}{l}\text { 1. Set a good example of Aeronautical Decision Making for } \\
\text { students. }\end{array}$ & 4.47 & 0.63 & .40 \\
$\begin{array}{l}\text { 2. After a lesson, review the poor decisions that were made } \\
\text { during the flight and ways to correct them with students. }\end{array}$ & 4.43 & 0.57 & .32 \\
$\begin{array}{l}\text { 3. Specifically evaluate students for their ability to exercise good } \\
\text { Aeronautical Decision Making. }\end{array}$ & 4.4 & 0.67 & .46
\end{tabular}


4. Explain their decision making process during flight so students can learn by example.

5. Place students in situations that encourage them to use good Aeronautical Decision Making procedures.

6. Encourage students to look for judgment errors during flight.

7. Introduce complex problems with time constraints and stress during flight training.

8. Allow students to make go/no go decisions for every flight and evaluate those decisions.

9. Incorporate realistic scenarios into lessons to develop decision making skills. $\begin{array}{lll}4.33 & 0.84 \quad .71\end{array}$

$\begin{array}{lll}4.17 & 0.75 \quad .56\end{array}$

$\begin{array}{lll}3.83 & 0.75 \quad .56\end{array}$

$3.77 \quad 1.01 \quad 1.01$

$3.73 \quad 0.98 \quad .96$

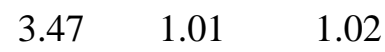

\section{Research Question 6: Is there a difference between the instructional methods that should be used to teach ADM and the instructional methods that are being used to teach ADM?}

After comparing the response means for Part I of the surveys, it was determined that five of the nine instructional methods surveyed revealed a significant difference at the $\mathrm{p}<.05$ level: setting a good example of ADM for students; encouraging students to actively look for ADM errors; introducing complex, time constrained, and stressful problems; allowing students to make go/no go decisions and evaluating those decisions; and the use of realistic scenarios (see Table 9). Interestingly, both the instructors and faculty reported the use of realistic scenarios as least used and least important, respectively. This was the case despite that it has been determined that situational techniques (i.e., scenarios that demanded the use of judgment) were the most effective method to develop decision making skills (FAA, 1991, 2008; Jensen \& Benel, 1977). Pilots need to practice and develop their decision making skills during flight training to compensate for their lack of experience; yet they are not afforded the opportunity to do so. The other areas of instructional methods were close to being in disagreement (p $<.05$ level), indicating that there is an overall disconnect between the methods the faculty members are expecting the instructors to use and the methods the instructors are actually using.

Table 9. Part I Statistical Analysis for the Professor and Instructor Surveys

\begin{tabular}{|c|c|c|c|c|c|}
\hline \multirow[b]{2}{*}{ Item } & \multicolumn{2}{|c|}{ Ranking } & \multirow[b]{2}{*}{$\mathrm{t}$} & \multicolumn{2}{|c|}{$95 \% \mathrm{CI}$} \\
\hline & Prof. & Inst. & & $\mathrm{p}$ & Sig. \\
\hline 8. Set a good example of Aeronautical Decision Making for students. & 1 & 1 & 2.20 & .03 & Yes \\
\hline $\begin{array}{l}\text { 1. Specifically evaluate students for their ability to exercise good } \\
\text { Aeronautical Decision Making. }\end{array}$ & 2 & 3 & 1.74 & .09 & No \\
\hline $\begin{array}{l}\text { 5. After a lesson, review the poor decisions that were made during the } \\
\text { flight and ways to correct them with students. }\end{array}$ & 2 & 2 & 1.89 & .07 & No \\
\hline
\end{tabular}


6. Encourage students to look for judgment errors during flight.

3. Place students in situations that encourage them to use good Aeronautical Decision Making procedures.

4. Introduce complex problems with time constraints and stress during flight training.

7. Explain their decision making process during flight so students can learn by example.

2. Allow students to make go/no go decisions for every flight and evaluate those decisions.

9. Incorporate realistic scenarios into lessons to develop decision making skills.

$\begin{array}{lllll}2 & 6 & 3.50 & .00 & \text { Yes } \\ 3 & 5 & 1.81 & .08 & \text { No } \\ 3 & 7 & 2.38 & .02 & \text { Yes } \\ 3 & 4 & 1.14 & .26 & \text { No } \\ 4 & 8 & 2.18 & .04 & \text { Yes } \\ 4 & 9 & 2.77 & .01 & \text { Yes }\end{array}$

\section{DISCUSSION AND CONCLUSIONS}

Training in judgment and decision making is effective in reducing the number of judgment errors that pilots make (Berlin, et al., 1982; Buch, et al., 1987; Buch \& Diehl, 1984; Connolly \& Blackwell, 1989; Telfer, 1989). Therefore, a flight training program should ensure that its students are receiving ADM training in pertinent areas. This study, like most studies, had some limitations. The population selected, small sample size, and low survey response rate, limit the generalizability of the results. However, these were considered practical limitations and do not necessarily affect the interpretation of the study's findings and conclusions. Another limitation is that since self-reporting was used in this study, it was assumed that the participants were frank and honest in their responses. However, there was the possibility that there were responses perceived to be socially acceptable or that what the instructors reported did not reflect what actually happened during instruction. Part II of the surveys revealed that the professor respondents believed that all elements surveyed were important to the development of ADM skills, and that the instructor respondents were not consistently incorporating the ADM elements. The comparative analysis of the professor and instructor responses from Part II of the survey led to the conclusion that the collegiate program examined had some areas in need of improvement in seven of the 22 elements of ADM. These areas consisted of risk management, course of action analysis, course of action selection, situation assessment, headwork, attitude management, and stress management. It is clear that an intervention is needed to strengthen these areas within the program.

Based on Part I of the professor and instructor surveys, the data indicate that the professor respondents believed that the majority of ADM instructional methods should be used in flight training, and that the instructor respondents were not using the methods of ADM instruction consistently in the aircraft. A comparison of the responses from Part I of the surveys also revealed that five of the nine methods of instruction showed significant differences in how ADM should be taught and how it was actually being taught. The methods of ADM instruction that revealed significant differences were setting a good example of decision making for students; encouraging students to identify judgment errors during flight; introducing complex, time constrained, and stressful problems during flight training; allowing students to make go/no go decisions for every flight; and incorporating realistic training scenarios into lessons. It can be concluded that instructors were not simulating some of the types of in-flight situations that could lead to an error in decision making.

The instructor survey included three items with respect to whether or not the instructor had received 
formal training with respect to how to teach ADM concepts, and where and when the training had occurred. Instructors who had training received it through the university. Several instructors reported that they had not received formal training; it is likely they obtained their CFI licenses outside of the university. Even so, the methods and elements used were similar between the two, concluding that the instructors who had received training were just as likely to omit ADM instruction as those who had not received training. In addition, neither group indicated that their students were provided opportunities to develop their ADM skills.

\section{Implications}

This study has revealed discrepancies between the level and quality of ADM instruction desired and what is being delivered. Accordingly, there are several implications for policy, practice, and research. The FAA and faculty of the university have not provided adequate guidance or enforcement regarding the use of ADM training to its instructors. The professors who participated in the study were all experienced in the field of aviation, and their input can aid in the development of new instructional policy. However, instructors were not implementing the ADM elements and instructional methods they learned during their flight and ground training; instructors should change the way they are teaching ADM in aircraft. Additionally, there has been insufficient research related to the status of ADM instruction. Although the FAA mandates that an applicant for a license must demonstrate good ADM, the training the students have received is not reflecting this mandate. Professors and instructors placed the use of scenarios at the bottom of their lists, which is a strong indication that the efforts of the FAA to encourage scenario-based training have not been entirely successful. In summary, students are not being exposed to the type of training that will allow them to develop into skilled decision makers. If ADM instruction is improved through training, continuous evaluation, and program improvement the possibility of an accident occurring will likely be reduced.

\section{Recommendations}

Several recommendations for policy, practice, and research were derived from this study. First, the FAA should strongly encourage the use of scenario-based training. The FAA has made great progress in recent years with the FITS program, and these efforts should continue. Second, flight training programs should constantly evaluate their flight training to determine if there is a need for improvement of ADM instruction, including student input. This study suggests one method for evaluating ADM training in a collegiate flight school. Once the evaluation is complete, instructor training programs should be developed to address those weak areas in ADM instruction. Students in the program should then be tested on their decision making ability during stage or phase checks to ensure that they are benefiting from the training. Lastly, flight training programs should be revised to include situations that allow the use of ADM. Other flight training programs could use the methods and survey procedures discussed in this study to conduct their own evaluations. It should require minimal additional funding and would benefit students and instructors by identifying weak areas for further development of ADM skills. 


\section{REFERENCES}

Abner, H. L. (2006). The essential elements of aeronautical decision making (Doctoral Dissertation). Available from ProQuest Dissertations and Theses database. (UMI No. 3206689)

Adams, R. J. (1994). Why aren't we teaching aeronautical decision making? Collegiate Aviation Review, $1-8$.

Aircraft Owners and Pilots Association. (2009). 2009 Nall report: Accident trends and factors for 2008. Retrieved from http://www.aopa.org/asf/publications/09nall.pdf

Belanger, B. (2001). The human side of decision-making. FAA Aviation News, 40, 8-12.

Berlin, J. I., Gruber, E. V., Holmes, C. W., Jensen, P. K., Lau, J. R., Mills, J. W., O’Kane, J. M. (1982). Pilot judgment training and evaluation - Volume I. Retrieved from http://www.dtic.mil/cgi-bin/ GetTRDoc?AD=ADA117508\&Location=U2\&doc=GetTRDoc.pdf

Bowman, T. S. (1993). Pilot judgment and decision-making training in post-secondary educational institutions (Doctoral Dissertation). Available from ProQuest Dissertations and Theses database. (UMI No. 9403057)

Brecke, F. H. (1981). Instructional design for aircrew judgment training. In Jensen, R. S. (Ed.), The First Symposium on Aviation Psychology (pp. 145-160). Columbus, OH: Aviation Psychology Laboratory, Ohio State University. Retrieved from http://www.eric.ed.gov/

Buch, G. D., \& Diehl, A. E. (1984). An investigation into the effectiveness of pilot judgment training. Human Factors, 26(5), 557-564.

Buch, G. D., Lawton, R. S., \& Livack, G. S. (1987). Aeronautical decision making for instructor pilots. Springfield, VA: National Technical Information Service.

Cassens, R. E. (2010). Elements Related to Teaching Pilots Aeronautical Decision Making (Master's thesis). Available from ProQuest Dissertations and Theses database. (UMI No. 1479648)

Connolly, T. J., \& Blackwell, B. B. (1989, January). A simulator-based approach to training in aeronautical decision making. Aviation, Space, and Environmental Medicine, 60(1), 50-52.

Diehl, A. E., Hwoschinsky, P. V., Livack, G. S., \& Lawton, R. S. (1987). Aeronautical decision-making for student and private pilots. Springfield, VA: National Technical Information Service.

Federal Aviation Administration. (1991). Aeronautical decision making. Retrieved from http://rgl.faa.gov/Regulatory_and_Guidance_Library/rgAdvisoryCircular.nsf/0/ CCDD54376BFDF5FD862569D100733983?OpenDocument

Federal Aviation Administration. (2003). Pilot's handbook of aeronautical knowledge. Oklahoma City, OK: U.S. Department of Transportation, Federal Aviation Administration, Airman Testing Standards Branch, AFS-630.

Federal Aviation Administration. (2008). Aviation instructor's handbook. Washington, D.C.: Federal Aviation Adminstration. 
Federal Aviation Administration. (2009). FAA FITS information. Retrieved from http://www.faa.gov/training_testing/training/fits/more

Federal Aviation Administration. (n.d.). Personal Minimums Checklist. Retrieved from http://www.faa.gov/training_testing/training/fits/guidance/media/personal\%20minimums\%20che cklist.pdf

Gall, M. D., Gall, J. P., \& Borg, W. R. (2007). Educational research: An introduction (8th ed.). Boston: Pearson Education, Inc.

Jensen, R. S. (1995). Pilot judgment and crew resource management. Brookfield, VT: Avebury Aviation.

Jensen, R. S., \& Benel, R. A. (1977). Judgment evaluation and instruction in civil pilot training (Report No. FAA-RD-78-24). Washington, D.C.: National Technical Information Service.

Joint Safety Analysis Team. (2002). General aviation aeronautical decision making. Retrieved from http://www.faa.gov/safety/programs_initiatives/

pilot_safety/safer_skies/gajsc/gajsc_documents/media/aeronautical.pdf

Kochan, J. A., Jensen, R. S., Chubb, G. P., \& Hunter, D. R. (1997). A new approach to aeronautical decision-making: The expertise method. Retrieved from http://handle.dtic.mil/100.2/ADA323793

Machado, R. (2009, Winter). Experience counts. InstructoReport, 3.

Nunnally, J. C., \& Bernstein, I. H. (1994). Psychometric Theory ( $3^{\text {rd }}$ ed.). New York, NY: McGrawHill, Inc.

Orasanu, J., \& Connolly, T. (1993). The reinvention of decision making. In G. Klein, J. Orasanu, R. Calderwood \& C. Zsambok (Eds.), Decision making in action: Models and methods (pp. 3-20). Norwood, N. J.: Ablex Publishing Corporation.

Orasanu, J., \& Fischer, U. (1997). Finding decisions in natural environments: The view from the cockpit. In C. Zsambok \& G. Klein (Eds.), Naturalistic decision making (pp. 343-357). Hillsdale, N. J.: Lawrence Erlbaum Associates.

Peterson, B. D. (2006). Do the right thing: Decision making for pilots. Retrieved from http://download.aopa.org/epilot/2006/sa24.pdf

Telfer, R. A. (1989). Pilot decision making and judgment. In R. S. Jensen (Ed.), Aviation Psychology (pp. 154-175). Aldershot, England: Gower Technical.

Wright, D. (n.d.). Building a box: A new tool for teaching good judgement. AOPA Flight Training. Retrieved from http://flighttraining.aopa.org/cfi_tools/ publications/inst_reports2.cfm?article $=4901$ 


\title{
The Marketability of Higher Education Aviation Graduates as Perceived by Regional Airline Pilots
}

\author{
James F. Fullingim, \\ Texas A\&M University Central Texas
}

\begin{abstract}
The purpose of this study was to expose any perceived inadequacies in the higher-education aviation curricula and to propose changes needed to better qualify aviation students in the hiring process at regional air carriers. The research also addressed the assumption that higher education is necessary for advancing a pilot's aptitudes and abilities to perform the highly technical tasks of a professional pilot in a regional airline environment. A survey was used to poll pilots from two regional airlines that were based in Texas. Analysis of the survey responses revealed the perceived quality of training that existed in higher education aviation programs. This confirmed the value of advising a path of higher education for students embarking on an aviation career as a pilot for a regional airline, and that 2-year colleges and 4year universities with aviation programs are meeting the present demands required by regional airlines in the south-central United States.
\end{abstract}

\section{INTRODUCTION}

Aviation collegiate programs have been traditionally viewed as a necessary path for students to obtain a professional aviation background as well as a college degree. In the past, professional pilots had an edge in the aviation market if they held a college degree because this added status to their marketability (Hunt, 1972). Obtaining aviation training from universities that offered aviation programs provided an even more marketable background for pilots and a degree with an aviation emphasis was considered to be even better (Clark, 2006).

Regional airlines hold 2-year colleges and 4-year universities with aviation programs in high esteem. It is also widely held that higher education is necessary for advancing a student's aptitudes and skills to perform the highly technical tasks of a professional pilot in a regional airline environment (U.S. Department of Education, 1998). This is in contrast with individuals that bypass the traditional role of higher education by taking shortcuts in an attempt to prepare themselves as pilots in the airline industry.

Two avenues that appeal to students desiring to obtain their aviation experience in order to prepare themselves for employment at the regional airlines are available at 2-year colleges and 4-year universities. These colleges and universities have specialized aviation programs for students wishing to obtain their flight certificates and ratings in an academic environment while receiving academic credit. Despite the perceived advantage of collegiate aviation programs in preparing students for careers in the airline industry, hiring qualifications for pilots in the regional airline industry have changed from past requirements, and new assessment is needed of the role of collegiate programs in the training of pilots who are entering the air carrier workforce.

The primary purpose of this research was to expose any perceived inadequacies in the highereducation aviation curricula and to propose changes needed to better qualify aviation students in the hiring process at regional air carriers. A secondary goal was to compare and contrast the role of 2-year colleges with aviation programs to the role of 4-year universities with aviation programs in the process of how students are educated for aviation flight careers.

Further scrutiny of higher education aviation programs is needed because of industry demands for greater competency from college flight program graduates entering the regional air carrier workforce (Mangan, 2000). These demands are due to the prevalent use of pure jet aircraft and their technical 
complexity, as well as the changing post-9/11 aviation environment. The increases in costs create training shortfalls and the industry has started to expect aviation universities to take measures to correct these deficiencies (Fanjoy et al., 2005). Already, in Asia, outside aviation training corporations are offering reduced-time types of advanced training courses through the use of computer simulation to teach piloting skills for new air carrier pilots. This type of training is called a multi-crew pilot license (MPL) training program, and it is indicative of one type of innovation being adopted by the air carrier industry (Matthews, 2006). If college program administrators fail to correct deficiencies within their programs, outside aviation training corporation sources will capitalize on the training shortcomings of graduate students that regional airlines expect of new-hire pilots (Mangan, 2000). This will increase the demand of training for future students elsewhere in pilot training corporations, thereby greatly reducing the need and role of aviation universities (Matthews, 2006).

Failure of college programs to adapt to the changes in the aviation industry could result in the cancellation of public higher education aviation programs, which would have numerous negative effects on pilots, including access to cost-effective public programs that over 100 colleges and universities presently offer (Prather, 2006). Other potential negative results from the reduction of collegiate aviation programs will be the emergence of substantially more expensive non-collegiate, commercial aviation schools, a further shortage of qualified pilots for air carrier positions in the United States, and the loss of airline flight operations internship programs that presently provide students with learning experiences that cannot be duplicated in classrooms (Ruiz, 2004).

Understanding the merits of higher education aviation programs is essential to continuing the collegiate path for the preparation of students interested in pursuing air carrier aviation as a career. The present transportation economy and the development of high-tech aeronautical equipment have changed the criteria that regional airlines use to hire entry-level pilots (Fanjoy et al., 2006). This, in turn, has led higher education to modify its aviation curriculum and to better qualify students for future careers in aviation.

\section{REVIEW OF THE LITERATURE}

The literature provides a good indication of what is taught in collegiate aviation courses and it supports the standards that regional air carriers require of aviation graduates. Collegiate aviation has been a major source of training in the United States and this has been recognized by the U. S. Department of Education (1998). Aviation industry leaders have recommended that airlines and universities form partnerships to jointly address the training and technology needs of the air carrier industry (Ruiz, 2004).

One important recent development in collegiate training courses has been the integration of crew resource management training for pilots. The responsibility of working well in a crew environment has best been put to practice in aircraft simulators at aviation universities (Hedge et al., 2000). The flight simulator is a valuable tool that helps prepare students for first officer training in the role of co-pilot during simulated flight sessions, as well as practice in crew resource management skills (Banard, 2000). Other schools have seen the importance of combining aviation courses with a liberal arts curriculum to provide situational awareness to create a better process of crew resource management in the aircraft cockpit (“Several Paths,” 2001).

The events of 9/11 led to catastrophic losses in the air carrier industry, which essentially halted pilot hiring in the U.S. aviation industry. Collegiate aviation programs reacted in numerous ways to keep pilot training aligned with the perceived present and future needs of the air carrier industry. Research showed that some prestigious aviation schools were no better in providing a specialized learning environment for pilot curriculum than outside, self-paced tutorials (Flouris, 2001). This awareness, along with concerns 
about the quality of aviation training in collegiate programs in the U.S., led to numerous attempts at improving the role of training, especially in a down-turned air transportation economy.

During this time, many aviation schools saw a decline in student enrollments. This led to case studies and independent audits to evaluate university programs in parallel with other universities and industry standards, and it also led to searches on how to revise aerospace programs (Schwab, 2005). Colleges have explored new training methods, including the application of distance education in aviation training. Training needs are forecast to grow for aviation at more than $40 \%$, and the need for online learning is seen as a technique to better meet this increased demand (Mahesh et al., 2005). Recent surveys have shown how students select collegiate aviation programs. Based on survey returns, the nine most frequently selected programs and institutional characteristics that attract students to collegiate aviation were program educational quality, university, condition of equipment, institutional educational quality, location of institution, small class size, safety concerns, student to faculty ratio, and distance from home (Clark, 2006).

The literature provides a good accounting of regional airline pilot hiring trends and future hiring considerations. Pilot positions in regional airlines have traditionally been entry-level jobs for collegiate aviation graduates. Regional airlines have a specific hiring criterion that is used to represent the level of flight training of entry-level pilots, while some hiring criteria are relaxed during periods of proficient entry-level pilot shortage (Matthews, 2006). Examples of relaxed times include the heavy use of computer simulation to teach piloting skills, as this reduces the total training time for first officers in the training of glass cockpit operational skills.

Regional airlines respond to positive economic conditions in the U.S. by expanding their routes according to higher public demand for air carrier service. In 1996, airlines earned record profits of \$2.8 billion and carried record numbers of passengers and amounts of cargo (Wells \& Wensveen, 2004). There has been an increase in demand for regional air carrier service and more pilots fly aircraft on these routes (Gilbert, 1994). Regional airlines lowered their minimum flight time requirements for new-hire pilots when they desperately were trying to recruit enough pilots to meet their staffing requirements (Fanjoy et al., 2006). This became more evident after industry expanded the role of smaller regional jet aircraft used in the U.S. air transportation system. These smaller, more efficient aircraft have replaced the older, larger jet aircraft that have been used by the legacy air carriers.

Another issue with huge ramifications is the mandated retirement age for air carrier pilots in the U.S., which is presently set at 65 years of age. The age issue illustrates the split in the airline staffing of pilots. Legacy carriers, struggling with high labor and pension costs, have an interest in replacing higher salaried pilots with younger pilots who earn less (Wolfe, 2005a). A high number of mandated pilot retirements results in a greater need for new pilots at the regional airline level. However, this retirement is highly contested by aviation union groups, which believe that senior pilots are being forced to retire at the peak of their performance and that the safety of passengers is compromised when they are replaced with younger, less experienced pilots.

All of this comes at a time when smaller regional jet aircraft are replacing the larger jet aircraft of the older legacy airlines. The legacy airlines have high fuel costs that are burning up their capital; competition is cutthroat, and two historical mainstays of the industry (Delta Airlines and United Airlines) were forced into bankruptcy (Wolfe, 2005b). Collegiate aviation programs have historically had to adjust their pilot training input to the fluctuating demands of the air carrier market. However, the emphasis of collegiate aviation remains that of offering, training, and graduating a product of excellence in aerospace curricula. 


\section{METHODOLOGY}

To explore the theory that regional airline air carrier pilots with a higher education background have marketability and preferential advantages over pilots without an academic background, a method was designed to ask specific questions of the pilots themselves. This was done by polling specific pilot groups with a user-friendly survey that was completed relatively quickly and anonymously. The style and format of this instrument determined how levels of higher education have aided pilots in modern regional airline pilot positions in the highly technical and demanding air transportation arena.

\section{Population}

The population surveyed for this study was limited to pilots employed at regional airlines, because the regional airlines are the first significant employer for a college aviation pilot graduate. The methodology in this survey was to recruit regional airline pilots in flight position status and to poll their opinions on marketability in the air carrier industry. These pilots represent graduates from 2-year and 4-year institutions with aviation programs, as well as pilots who completed no formal higher education aviation courses. The specific samples came from 2 large Texas-based regional airlines, American Eagle of AMR, Inc., and Express Jet Airlines, Inc. These two regional airlines have vast domestic and international routes across North America and operate both turboprop and turbojet aircraft in their fleets.

\section{Sample}

The initial pilots surveyed at each of these two companies were students who graduated from the Tarleton State University - Central Texas 4-year aviation program and were employed in flight positions. Their employment in the regional air carrier industry was ideal for this study's questions concerning the background of higher education training and how prior training has qualified them for their present occupations as pilot crew members in regional airline air carriers. Along with the aforementioned pilots, other pilot crew members at these various domiciles were contacted by the researcher's graduate aviation students. These crew members were first officers and captains who were employed in the same aircraft types and flight assignments to which Tarleton graduates are assigned. All of these initial pilots were graduate acquaintances of the researcher and performed the same tasks and duties in assigned flight positions at the Dallas-Fort Worth (DFW) and Houston domiciles. This was an accessible method because all pilot employees had personal mail boxes in which the survey instruments were placed.

The domiciles at both the DFW and Houston locations were large, with 940 pilots employed with American Eagle and over 1,000 pilots with Express Jet. The sample size at each location was as few as 30 , with a maximum of 100 . This brought a maximum percentage of $10 \%$ polled at each location, with 200 surveys utilized. The administered sample was a combination of random and convenience. This is because the Tarleton graduate pilots distributed the survey in pilots' workplace mailboxes, as well as physically handed them to the crewmembers they were working with on a particular flight. Because of this personal touch, a high number and percentage of returns resulted.

\section{Research Design}

To properly document the past flight training of pilots who are presently employed at a particular regional airline, a survey instrument was used to collect information from pilots who had been hired by and worked for the respective regional airlines at the time the survey was administered. The instrument surveyed the background and qualifications of the individual pilot who had successfully been interviewed, employed, trained, and placed in a flight position. Questions regarding educational background were specifically included in the survey, along with inquires as to age, gender, and race. Past studies performed with regional airline personnel indicate that these regional airline employers are not overly 
concerned with pilot applicants having a higher education degree or background (Fanjoy et al., 2006). Therefore, the main objective of the survey was to poll individuals who (a) had qualified to be airline pilots; (b) had gone through a regional airline interview process; (c) had been offered and accepted employment with the specific regional airline, followed by successfully completing all phases of company training; and (d) were actively employed as pilots in a flight position.

\section{Instrument}

A pilot survey was developed and field tested on a group of pilots for input and possible modifications. The survey instrument was developed in a Likert scale format that asked the respondents to reply to specific questions pertinent to their aviation background. Additional data questions on the survey were developed in the areas of aviation education, qualifications obtained prior to being hired at their present airline, abilities perceived to be critical in the airline industry, and present job satisfaction. These questions were designed to determine relationships between college status and non-college status and how these backgrounds affected employability. The proposed instrument was a printed questionnaire with a return postage-paid envelope for the respondents to complete. This format was carefully chosen because access to individual pilot inter-office mail boxes was obtainable through graduate pilot acquaintances. Follow-up information on the results of the survey was made available to individuals taking the survey, provided the writer had access to their individual email addresses. The physical paper mail survey was preferred because it offered greater anonymity, less intimidation, less expense to the subject completing the survey, and a higher completion return than the online electronic survey.

As an incentive, a gratuity in the amount of a one-dollar bill was placed in each survey document. This incentive was expected to increase the rate of completion and return for the survey instruments. This particular incentive was chosen over a gift card because the expense was less and the monetary amount was deemed insignificant to be appreciated by the pilot recipients.

\section{Collection and Treatment of Data}

Three graduates from the Tarleton State University - Central Texas Aviation Program had access to this population inside their two workplaces. These packets were either personally handed to the recipients or placed in their company mailboxes. One hundred and three of the 200 distributed surveys were returned by mail during the duration of the study, for a return of $51.5 \%$. All of the returned surveys were entered into an Excel spreadsheet. Forty-seven different columns were used to enter answers for each question. Written comments were all transcribed and entered into one separate column. Procedures utilized frequency and percentage distributions for data analysis on the nominal and ordinal scale. Mean scores and standard deviations on interval data were gathered from the Likert scale questions.

\section{Quantitative Research Related Data Questions}

The first 22 questions of the survey were based on the respondent's opinion regarding past education issues, and the choices for responses were Likert scale selections in a range from 1 to 4 ( 1 = strongly disagree to $4=$ strongly agree). The last selection, five, was not used in tabulating the results. This selection was left on the survey instrument to discourage the person taking the survey from picking an average selection in the middle of the scale. Four themes were designed into the 22 questions: school and academics, satisfaction with academic programs, employment, and workplace opportunities with challenges. From the first 22 questions on the survey, questions 1, 2, 4, 7, 8, 9, 12, 13, 14 and 16 pertained to school and academics. Questions 3, 5, 6, 10, 11, 15, and 17 pertained to satisfaction with academic programs. Questions 19, 20 and 21 pertained to employment. Questions 4, 17, 18 and 22 pertained to workplace opportunities with challenges. 
To determine whether the questionnaire had kept with the issue of pilot marketability in the regional airline industry, the returned answers were tested statistically using the SPSS version 15 exploratory factor analysis to see whether a trend existed among the questions. Of these first 22 questions, 4 themes appeared: school and academics, satisfaction with academic programs, employment, and workplace opportunities with challenges.

Table 1. Factor Analysis for Survey Data: Total Variance Explained

\begin{tabular}{|c|c|c|c|c|c|c|}
\hline Component & \multicolumn{3}{|c|}{ Initial Eigenvalues } & \multicolumn{3}{|c|}{$\begin{array}{l}\text { Extraction Sums of Squared } \\
\text { Loadings }\end{array}$} \\
\hline $\begin{array}{l}\text { (not specific } \\
\text { questions) }\end{array}$ & Total & $\begin{array}{c}\% \\
\text { Variance }\end{array}$ & $\begin{array}{c}\% \\
\text { Cumulative }\end{array}$ & Total & $\begin{array}{c}\% \\
\text { Variance }\end{array}$ & $\begin{array}{c}\% \\
\text { Cumulative }\end{array}$ \\
\hline 1 & 7.145 & 32.476 & 32.476 & 7.145 & 32.476 & 32.476 \\
\hline 2 & 4.038 & 18.356 & 50.832 & 4.038 & 18.356 & 50.832 \\
\hline 3 & 2.890 & 13.135 & 63.968 & 2.890 & 13.135 & 63.968 \\
\hline 4 & 2.594 & 11.792 & 75.760 & 2.594 & 11.792 & 75.760 \\
\hline 5 & 2.024 & 9.201 & 84.961 & 2.024 & 9.201 & 84.961 \\
\hline 6 & 1.391 & 6.323 & 91.284 & 1.391 & 6.323 & 91.284 \\
\hline 7 & .866 & 3.938 & 95.222 & & & \\
\hline 8 & .633 & 2.878 & 98.101 & & & \\
\hline 9 & .299 & 1.358 & 99.459 & & & \\
\hline 10 & .119 & .541 & 100.000 & & & \\
\hline 11 & 3.10E-016 & $1.41 \mathrm{E}-015$ & 100.000 & & & \\
\hline 12 & 2.33E-016 & 1.06E-015 & 100.000 & & & \\
\hline 13 & 1.93E-016 & 8.77E-016 & 100.000 & & & \\
\hline 14 & 8.78E-017 & 3.99E-016 & 100.000 & & & \\
\hline 15 & 3.87E-017 & 1.76E-016 & 100.000 & & & \\
\hline 16 & 1.85E-018 & 8.42E-018 & 100.000 & & & \\
\hline 17 & $-1.50 E-017$ & $-6.80 E-017$ & 100.000 & & & \\
\hline 18 & $-9.29 E-017$ & $-4.22 E-016$ & 100.000 & & & \\
\hline 19 & $-1.40 \mathrm{E}-016$ & $-6.38 E-016$ & 100.000 & & & \\
\hline 20 & $-1.96 \mathrm{E}-016$ & $-8.90 E-016$ & 100.000 & & & \\
\hline 21 & $-2.33 E-016$ & $-1.06 E-015$ & 100.000 & & & \\
\hline 22 & $-2.93 E-016$ & $-1.33 E-015$ & 100.000 & & & \\
\hline
\end{tabular}

Note. Extraction Method: Principal Component Analysis.

The data were entered into SPSS and a principal component analysis was conducted. Six components resulted from the Extraction Method of the Principal Component Analysis. Component 1 had the highest loading accounting for $32.47 \%$ of the variance, which was identified as school and academics. Once the factors were determined, the items belonging to each component were summed and correlational analyses were performed on the components to investigate relationships between the subscales. Table one lists the loading of the 6 components from the analysis of the data from the 22 questions.

Table two lists the extractions of the 6 components, with each of the 22 questions listed in order of the variance. VAR000111 is survey question 11, and VAR00012 is survey question 12 . Component column 1 with the entries of .911, .830, .747, .737, .718, -.702, .693, -.682, -.627, .588, and .522 sequentially 
illustrate the highest component loading of 11 specific survey questions, with .911 being the largest variable question from the component 1 entries.

Table 2. Component Matrix(a)

\begin{tabular}{|l|c|c|c|c|c|c|}
\hline & \multicolumn{7}{|c|}{ Component } \\
\hline Questions 1- 22 & 1 & 2 & 3 & 4 & 5 & 6 \\
\hline VAR00011 & .911 & -.031 & -.113 & .128 & .000 & .259 \\
VAR00012 & .830 & .316 & -.189 & -.193 & .225 & -.143 \\
VAR00005 & .747 & -.098 & .222 & -.399 & .308 & .107 \\
VAR00010 & .737 & .448 & -.018 & .047 & .292 & .344 \\
VAR00009 & .718 & -.611 & .252 & -.094 & -.025 & .011 \\
VAR00018 & -.702 & -.441 & .002 & -.376 & .277 & .132 \\
VAR00015 & .693 & .088 & -.162 & .102 & -.355 & -.419 \\
VAR00016 & -.682 & -.056 & .132 & -.175 & .661 & -.067 \\
VAR00013 & -.627 & .364 & .275 & .537 & .175 & -.040 \\
VAR00002 & .588 & -.274 & -.103 & .375 & -.453 & .384 \\
VAR00001 & .552 & .536 & -.329 & .015 & .083 & .307 \\
VAR00017 & .232 & .837 & -.090 & -.109 & .082 & -.256 \\
VAR00019 & .180 & .748 & .582 & -.083 & .058 & -.200 \\
VAR00008 & .460 & -.726 & .267 & .329 & .166 & -.009 \\
VAR00007 & .585 & -.610 & -.080 & .274 & .434 & -.067 \\
VAR00020 & .109 & -.406 & .833 & .043 & -.073 & -.269 \\
VAR00021 & .094 & .113 & .791 & -.380 & -.115 & .328 \\
VAR00003 & -.047 & .202 & .707 & .382 & -.083 & .304 \\
VAR00022 & .487 & .247 & .342 & -.673 & .029 & .062 \\
VAR00014 & -.444 & .390 & .073 & .614 & .217 & .394 \\
VAR00004 & .462 & .244 & .343 & .595 & -.038 & -.424 \\
VAR00006 & .464 & -.049 & -.085 & .283 & .781 & -.108 \\
\hline
\end{tabular}

Note. Extraction Method: Principal Component Analysis; 6 components extracted.

The resulting analyses showed significant correlations between academics and employment $(r$ [87]= $.622, p=.000)$, academics and opportunity $(r[89]=.217, p=.039)$, and challenge and opportunity $(r[88]=.302, p=.004)$. From these 4 themes of school and academics, satisfaction with academic programs, employment, and workplace opportunities with challenges, strong correlations existed between academics and employment, academics and opportunity, and challenges and opportunity. Academics had the strongest correlations from all of the themes.

Next, a series of independent samples $t$-tests were run with the same SPSS program to see whether there were any differences between the subscale items of captains and first officers for the 4 themes of school and academics, satisfaction with academic programs, employment, and workplace opportunities with challenges. The results from conducting the series of $t$-tests on these variables of interest showed that there were no significant differences between the captains and first officers on three of these themes. However, the $t$-test did show a statistically significant difference for the theme of opportunity in the comparison between captains and first officers $(t(89)=3.134, p=.002)$. This gave a distinct advantage to first officers scoring higher in the opportunity theme than the results scored for the captains. 


\section{Demographic Research-Related Data Questions}

The data section of the survey had questions pertaining to the background of the pilots taking the survey. Questions 23 through 47 asked for descriptive information that pertained to school/academics and present employment. Most of the pilots completed this data section, and their answers could be cross-referenced with other questions in the data section.

Questions 23 and 24 qualified the pilots' sex and age. Of the 91 respondents, 87 were male (96\%), with an average age of $37.80(S D=9.54$ years $)$.

Table 3. Independent Samples t-Tests

\begin{tabular}{llllll}
\hline Variable & $t$ & $d f$ & $p$ & Mean Difference & SE \\
\hline Academics & 1.929 & 89 & .057 & 2.47 & 1.28 \\
Employment & 1.430 & 87 & .156 & 1.14 & 0.79 \\
Opportunity & 3.134 & 89 & $.002^{*}$ & 1.24 & 0.39 \\
Other & 1.170 & 88 & .245 & 0.49 & 0.42 \\
\hline$*<05$ & & & & &
\end{tabular}

$*<.05$

Question 26 dated the pilots' entry into aviation by asking for the date of first solo. The date was converted into years and months from the earliest time listed and subtracted from the most recent date of September 2007. This gave the average number of years that the pilots had been flying at 16.92 years $(S D=9.57)$. This is also a level of experience data indication.

Question 27 asked for the total flight hours that the pilots had accrued. The combined captains and first officers had an average total flight time of 7,693 hours $(S D=5515.94)$. This flight time could be further broken down between first officers and captains in order to reflect the total experience of the different pilot flight positions. This question could also be analyzed with other questions, such as question 33, in order to collect additional data on the time pilots have accrued since being employed at their present airline. This would better qualify the experience level that pilots have in the workplace today.

Questions 28 and 29 asked for CFI Certificate and total CFI time (Certified Flight Instructor). These questions qualify the background of the individual taking the survey in relation to how they built their flight time during and after their academic flight training. They also indicate the process of how crew coordination is learned between 2 pilots in one airplane. Out of the 91 respondents, $78(85.7 \%)$ had their CFI rating, and total CFI flight hours were 1,663.

Questions 32, 33, and 34 helped qualify the employment requirements of the employers for the pilots taking the survey. These numbers can be analyzed as a benchmark that employers establish for pilots to qualify for employment consideration with specific flight times.

Question 33 compares and contrasts the years that pilots have been employed at the specific regional airline and in the capacity of captain or first officer. This number is valuable to determine the new hire rate, upgrade time from first officer to captain, and attrition rate at the specific regional airline. Of the 91 respondents, 49 (53.8 \%) were captains and 42 (46.1\%) were first officers. Captains indicated that they 
had been employed at the specific regional airline for an average of 17.3 years, and first officers had been employed for an average of 4.5 years $(S D=6.87)$.

Question 36 measured the highest level of education that the pilots had completed. The entry for bachelor's degree had the highest completion rate of all the levels measured. Out of 91 respondents, 64 (70.3\%) attained the bachelor's degree. No other degree selections came close to this figure.

Questions 38 through 47 were queries into specific collegiate data fields. Significant high percentage numbers from these questions help determine the quality of the collegiate program that prepared respondents for their regional airline careers.

Question 38 gives information on the connection of bridge programs between regional airlines and aviation universities. This is invaluable information pertaining to the importance of regional airlines being involved in the training process with higher education aviation programs. Out of 91 respondents, 12 (13.1\%) graduated from a bridge program for a regional airline. Question 40 is extremely valuable because it measures the number of pilots who obtained an aviation degree from higher education aviation programs. Out of 91 respondents, 53 (58.2\%) obtained an aviation degree. The last question, 47, is an indicator of how flight schools directly control the access and use of training aircraft. Out of 91 respondents, 75 individuals (82.4\%) indicated that the school owned their own aircraft.

\section{Survey Respondents’ Comments With Qualitative Data Themes}

All of the recorded written comments that respondents left on their surveys were compared for similarities to the 4 themes that were correlated from the quantitative data of the first 23 questions of the survey. The themes that emerged were school and academics, satisfaction with academic programs, employment, and workplace opportunities with challenges. Of these themes, academics were the predominant concern in the comments.

\section{RESULTS}

Three research questions were examined to expose any perceived inadequacies in higher education aviation curriculum, and to compare and contrast the role of 2-year colleges with aviation programs to the role of 4-year universities with aviation programs.

\section{Research Question 1: Is higher education advisable for students embarking on an aviation career as a pilot for a regional airline?}

Responses from the first 22 Quantitative Research questions had academics with the most correlations. In this section, First Officers scored higher responses than Captains. Captains responded more frequently in the Disagree areas of these questions. Responses from the Data Research questions had a high percentage of results in academic areas. $70.3 \%$ had a Bachelor's Degree, with $58.2 \%$ completing an aviation degree. The high percentage response for completing a Bachelor's Degree confirmed the need and perceived requirement for higher education in a regional airline career. Responses from the Respondent's Comments questions had mixed results, but the majority left favorable remarks on the importance of obtaining a degree to improve pilot chances of being hired in the regional airline industry. First Officers left the most favorable responses to the value of their higher education degrees and were the most adamant about obtaining their present employment due to higher education. 


\section{Research Question 2: Have 2-year colleges and 4-year universities with aviation programs kept up}

with the requirements for employability with the regional airlines?

Responses from the first 22 Quantitative Research questions had employment opportunities as a high return. Reponses in this area indicated a majority satisfaction with employment opportunities that were created by higher education aviation programs. Responses from the Data Research questions were limited in being related to this research question, but several questions indicated some response to higher education aviation programs being current for the needs of regional airlines. Responses from the Respondent's Comments questions dealt mostly with staffing shortages and workplace conditions. However, the few comments that were made on employability that was due to higher education aviation programs were favorable.

\section{Research Question 3: Can higher education aviation programs properly measure and critique their programs in regard to the qualifications that students need to embark on a career as a regional airline pilot?}

There were responses from the first 22 Quantitative Research questions that were interpreted to critique and measure higher education programs. These questions dealt with training accountability and how the respondent felt they had an advantage in being hired by the regional airlines. Most of the responses were made in the Strongly Agree section, and this verified the research question of aviation colleges being able to critique their programs. Responses from the Data Research questions were limited in making connections to aviation college accountability due to the nature of the questions, and no real connections could be made. Responses from the Respondent's Comments questions had numerous direct connections to the merit, worth and accountability of higher education aviation programs in reference to preparing aviation students for the regional airlines. The comments dealt with schools that were accountable in the preparation for students being adequately trained for the airlines, and comments were mixed in the esteem held for former colleges. Comments made ranged from avoiding over-priced schools, advantages of formal ground courses, the lack of college job placement, and the lack of a formal CFI (Certified Flight Instructor) school. The overall response was that higher education aviation programs can properly measure and critique their programs if they desire to meet the needs of their students.

\section{DISCUSSION}

Pilot needs by the regional airlines over the last decade have challenged collegiate aviation to produce enough pilots to meet their future staffing requirements. Out of this need, allowances have been made by the airlines to accelerate the process in which qualified pilots can be hired and trained to meet the standards required by the FAA and regional airline training departments. In this environment, 2-year colleges and 4-year universities with aviation programs have had to compete with outside markets to qualify, train, and graduate a better student product that is ready to be integrated into the regional airlines. Today's aviation graduates will have to blend with older pilots who were trained differently in the past and must bridge the gaps that exist between the new and the old procedures of getting started in the regional airline industry.

The majority of the pilots completing the survey had a 4-year degree (70.3\%). This was common from new hires to much older experienced captains. By tabulating the results, the 4-year degree is still the standard that pilots desire to obtain, although the major of aviation is inconclusive; $58.2 \%$ possessed a 4 year aviation degree. Those who responded to the subject of degree specialty were split on whether the type of degree was important. 
Several captains were impressed with the quality and caliber of training that new hires possessed, but they were concerned about the lack of total flight time and lack of outside experience of the younger first officers hired. First officers surveyed were far more optimistic about their future and displayed a higher level of confidence in the attainment of their flight positions. The first officers also had a greater appreciation of their higher education backgrounds and expressed an opinion that this background was a deciding factor on their being hired at their airline. The first officers also gave favorable remarks concerning the level of training they received at their collegiate flight schools, whereas many captains came from nontraditional flight schools that were not associated with higher education. Pilots completing the surveys gave their aviation colleges and aviation universities favorable remarks for curriculum, technical expertise, and modernization for aeronautical training. This pattern was even higher with first officers.

The survey showed no alarming levels of inadequacies that existed in the higher education aviation curricula, nor did it find that major changes were needed to better qualify aviation students in the hiring process at regional air carriers. Most comments made on issues of past training came from concerns about the expenses incurred and the burden of repaying large student loans. Pilots have traditionally gained experience after graduation when they have the aviation certificates and ratings obtained at their respective aviation colleges and universities. These same colleges and universities often employ their graduates as Certified Flight Instructors to gain experience by training other students.

There was little difference found in pilots' preferences of 2-year colleges with aviation programs when compared to 4-year universities with aviation programs in the process of how students were educated for aviation flight careers. The surveys showed that the majority of the pilots with aviation degrees graduated with a 4-year degree, but the 2-year degree graduates spoke very favorably of their aviation schools.

One captain recommended that a new collegiate course of study should be created to help students plan and forecast their seniority with prospective air carriers. This course would include a research of the pilot age group broken down by percentage, a forecast of retirees in each year over the next ten years, a research of the industry growth cycle, a tabulation of the entire industry growth cycle, and the anticipated student age when hired by the 14 CFR Part 121 operator of their choosing.

Many findings in the analysis of the survey and the comments from the respondents found issues parallel to those stated in the review of the literature. Some of these examples were the mentioning that collegiate aviation has been a major source of training in the United States, and that the downsizing of the military has led to a dependence on the civilian field. Other parallels were the lowering of standards for entry-level pilots by the regional airlines in times of pilot shortages and the concern that regional airlines are desperately trying to recruit enough pilots to meet their staffing requirements.

\section{RECOMMENDATIONS}

As hiring criteria for regional airlines change, higher education will confer an advantage to students seeking employment with an air carrier, but the training process must continue to be tailored to meet the needs of the air carriers' workplaces. Ground school curricula and flight courses must be coordinated to meet the present day needs of the regional airlines, and agreements must be in place between the airlines and the curricula of the aviation schools to meet the needs and demands of the airline industry. The superior package of an aviation college degree offers the combined package of aviation training and college core components to provide this training for a career in the air carrier industry.

The choice students make in pursuing an aviation career at an early age is a challenge. They must take the correct steps to successfully accomplish the dream of flying, but it is also vital that they make the ideal academic choices for preparation in this career. The major commitment students make to pursue an 
airline career must be approached as steps toward a career in air carrier operations, not a weekend hobby that must be supported by another job.

To offer a quality product in the training field, 2-year colleges and 4-year universities with aviation programs must increase their offerings for CFI programs, and they must push for a higher completion rate. The process of creating a quality degree program to obtain the CFI rating that is more accessible to aviation students must be implemented in a larger number of higher education aviation programs.

Academic degree plans with minors outside of aviation give prospective students an insight into additional fields. Further higher education in graduate fields is also an option, with master's degrees being obtainable through distance learning programs that are more accessible to pilots. This type of diversification makes aviation students more competitive in not only the air carrier industry but in other facets of aviation as well.

Future studies could explore how regional airlines could tailor specialized pilot training agreements with 2-year colleges and 4-year universities with aviation programs, both academically and financially. Added incentives for the student could be financial aid, flight time building grants, and a higher initial salary upon being hired by the airline after the student graduates. This could add needed resources to the schools to better qualify potential students from the onset of training and eliminate lost time and financial resources.

\section{CONCLUSION}

Two-year colleges and 4-year universities with aviation programs are meeting the demands made by the regional airlines, but pilot shortages of the past have presented challenges to the system to produce more pilot graduates in less time. Disparities exist between older crew members and younger, less experienced new-hires because of the demands of the staffing shortage of the regional airlines. With this shortage, the pressing issues of how to train and hire qualified pilots to fly technologically advanced regional airline jet aircraft have forced the industry to demand more aviation skills from a shrinking market of aviation pilot candidates.

Aviation students recognize the worth and value of a 4-year degree and that obtaining this degree creates a distinct marketing advantage in being hired by both the regional airlines and later legacy major airlines. Also, there is an advantage in obtaining a 4-year aviation degree because of the experience gained in a collegiate aviation environment. 


\section{REFERENCES}

Banard, K. R. (2000 April). Ascend to flight training. Tech Directions, 59(9), 26.

Clark, J. (2006). The face of collegiate aviation: Factors impacting self-selection of collegiate aviation programs. Collegiate Aviation Review, 24(1), $42-57$.

Damos, D. (1996). Pilot selection batteries: Shortcomings and perspectives. International Journal of Aviation Psychology, 6(2), 199.

Dennison, G. M. (2003). Privatization: An unheralded trend in public higher education. Innovative Higher Education, 28(1), 7-20.

Fanjoy, R. O., Young, J. P., \& Dillman, B. G. (2005). Exit exams for college flight programs: Redundant activity or certification of competency? Collegiate Aviation Review, 23(1), 24-31.

Fanjoy, R. O., Young, J. P., \& Suckow, M. W (2006). The experience factor: A regional airline view of pilot candidate qualifications. Collegiate Aviation Review, 24(1), 67- 72.

Flouris, T. C. (2001). The impact of ground schools in a collegiate aviation program on FAA written exam scores. Collegiate Aviation Review, 19(1), 49-61.

Gilbert, G. A. (1994). U.S. regional airlines report substantial growth. Business \& Commercial Aviation, 75, 20.

Hedge, J. W., Bruskiwicz, K. T., Borman, W. C., Hanson, M. A., Logan, K. K., \& Siem, F. M. (2000). Selecting pilots with crew resource management skills. International Journal of Aviation Psychology, 10(4), 377-392.

Hunt, J. R. (1972). The role of the aviation university. Education, 92(4), 2-4.

Lindseth, P. A. (1999). Assessing the environment and outcomes of 4-year aviation programs: Does program quality make a difference? Collegiate Aviation Review, 17(1), 40-52.

Mahesh, S., Chowdhury, M., Colquitt, C., Reyes, P., Bonakdar, N., Ray, J., \& Robles, J. (2005). Distance education in the business aviation industry: Issues and opportunities. Journal of Distance Education Technologies, 3(1), 20-43.

Mangan, K. (2000, January 21). Aviation centers take off as airlines face pilot shortage. Chronicle of Higher Education, 46(20), 47-48.

Matthews, N. (2006, April 17). Alteon formulates multicrew pilot license course in Brisbane for Asian airlines. Aviation Week \& Space Technology, 164(16), 44.

Prather, C. D. (2006). The council on aviation accreditation: Part one- historical foundation. Journal of Air Transportation, 11(2), 156-177.

Ruiz, J. R.(2004). The perceived value of airline flight operations internship activities and/or benefits in the pursuit of career goals. Collegiate Aviation Review, 22(1), 71- 82. 
Schwab, G. L. (2005). An examination of the Indiana State University aerospace administration program. Journal of Air Transportation, 10(10), 72-103.

Several paths available for aviation candidates. (2001, October 8). Aviation Week \& Space Technology, 155(15).

United States Department of Education. (1998, September 14). Taking flight: Education and training for aviation careers. Retrieved from http://www.ed.gov/offices/OUS/PES/higher/civilai2.html

Wolfe, K. (2005a, January 31). Older pilots find not-so-friendly skies. CQ Weekly, 218.

Wolfe, K. (2005b, April 25). Rough skies for the 'big six.’ CQ Weekly, 1068.

Wells, A. T., \& Wensveen, J. G. (2004). Air transportation, a management perspective, ( ${ }^{\text {th }}$ ed.). San Francisco: Thomson Brooks-Cole. 


\section{Regional Airline PILOT SURVEY}

\begin{tabular}{|c|c|c|c|c|c|}
\hline Question & $\begin{array}{l}\text { Strongly } \\
\text { Disagree }\end{array}$ & Disagree & Agree & $\begin{array}{c}\text { Strongly } \\
\text { Agree }\end{array}$ & $\begin{array}{c}\text { Not } \\
\text { Applicabl } \\
\text { e }\end{array}$ \\
\hline $\begin{array}{l}\text { 1. I learned about my flight school through } \\
\text { acquaintances that recommended me this } \\
\text { particular school. }\end{array}$ & 1 & 2 & 3 & 4 & 5 \\
\hline $\begin{array}{l}\text { 2. My initial expectations were met at my flight } \\
\text { school from the time I started flight training to } \\
\text { the completion of my aviation courses. }\end{array}$ & 1 & 2 & 3 & 4 & 5 \\
\hline $\begin{array}{l}\text { 3. I received a good value for the money } \\
\text { I invested at my flight school. }\end{array}$ & 1 & 2 & 3 & 4 & 5 \\
\hline $\begin{array}{l}\text { 4. I was motivated and challenged by my flight } \\
\text { instructors during my flight school training. }\end{array}$ & 1 & 2 & 3 & 4 & 5 \\
\hline $\begin{array}{l}\text { 5. The level of avionics at my basic flight } \\
\text { school was adequate for the basic instrument } \\
\text { skills I use in my present flight position. }\end{array}$ & 1 & 2 & 3 & 4 & 5 \\
\hline $\begin{array}{l}\text { 6. Membership in the Alpha Eta Rho aviation } \\
\text { fraternity was a factor that increased my } \\
\text { aviation marketability. }\end{array}$ & 1 & 2 & 3 & 4 & 5 \\
\hline $\begin{array}{l}\text { 7. My aviation ground school academic subjects } \\
\text { were coordinated to be taken at the same time } \\
\text { I took specific flight courses. }\end{array}$ & 1 & 2 & 3 & 4 & 5 \\
\hline $\begin{array}{l}\text { 8. I was motivated and challenged by my } \\
\text { academic } \\
\text { professors during my aviation classroom } \\
\text { training. }\end{array}$ & 1 & 2 & 3 & 4 & 5 \\
\hline $\begin{array}{l}\text { 9. My basic non-aviation academic core } \\
\text { components } \\
\text { were blended well with my aviation curriculum } \\
\text { to } \\
\text { produce a well-rounded degree. }\end{array}$ & 1 & 2 & 3 & 4 & 5 \\
\hline $\begin{array}{l}\text { 10. My school was concerned for my future } \\
\text { marketability in air carrier employment. }\end{array}$ & 1 & 2 & 3 & 4 & 5 \\
\hline $\begin{array}{l}\text { 11. I am satisfied with the amount of time it } \\
\text { took } \\
\text { to complete my aviation degree. }\end{array}$ & 1 & 2 & 3 & 4 & 5 \\
\hline $\begin{array}{l}\text { 12. My academic advisor adequately prepared } \\
\text { me for the air carrier industry where I was later } \\
\text { employed. }\end{array}$ & 1 & 2 & 3 & 4 & 5 \\
\hline 13. I completed most of my aviation training & 1 & 2 & 3 & 4 & 5 \\
\hline
\end{tabular}




\begin{tabular}{|c|c|c|c|c|c|}
\hline $\begin{array}{l}\text { outside } \\
\text { of the college where I received my degree. }\end{array}$ & & & & & \\
\hline $\begin{array}{l}\text { 14. I received my flight training outside of a } \\
\text { university collegiate environment, and I found it } \\
\text { superior to that of an aviation university. }\end{array}$ & 1 & 2 & 3 & 4 & 5 \\
\hline $\begin{array}{l}\text { 15. If I could return to my freshman year, I } \\
\text { would choose the same major I completed with } \\
\text { my degree. }\end{array}$ & 1 & 2 & 3 & 4 & 5 \\
\hline $\begin{array}{l}\text { 16. Distance learning was an important factor in } \\
\text { completing my college degree. }\end{array}$ & 1 & 2 & 3 & 4 & 5 \\
\hline $\begin{array}{l}\text { 17. Based on my collegiate training, I was well } \\
\text { prepared for my interview with my present } \\
\text { employer. }\end{array}$ & 1 & 2 & 3 & 4 & 5 \\
\hline $\begin{array}{l}\text { 18. My academic background had no factor on } \\
\text { my } \\
\text { being selected by my present airline. }\end{array}$ & 1 & 2 & 3 & 4 & 5 \\
\hline $\begin{array}{l}\text { 19. My college training and degree put me at an } \\
\text { advantage over applicants with no college } \\
\text { training } \\
\text { when I was hired by my current employer. }\end{array}$ & 1 & 2 & 3 & 4 & 5 \\
\hline $\begin{array}{l}\text { 20. I was hired at this airline due to my } \\
\text { trainability } \\
\text { in aviation skills. }\end{array}$ & 1 & 2 & 3 & 4 & 5 \\
\hline $\begin{array}{l}\text { 21. I was hired at this airline due to my past } \\
\text { operational background in aviation. }\end{array}$ & 1 & 2 & 3 & 4 & 5 \\
\hline $\begin{array}{l}\text { 22. Based on my past training at my aviation } \\
\text { school, } \\
\text { I am satisfied with my current aviation status. }\end{array}$ & 1 & 2 & 3 & 4 & 5 \\
\hline
\end{tabular}

23. Sex: $\mathrm{M}_{-} \mathrm{F}$

24. Age:

25. Race:

26. Date of first solo:

27. Total flight hours:

28. CFI Certificate: YES NO

29. Hours as CFI:

30. Part 135 Hours:

31. Part 91 Corporate Hours: 
32. Number of hours when hired by present airline:

Single Engine: Multi Engine:

Turbine Engine:

33. Years employed at present airline:

34. Present Flight Position:

35. Former military pilot: YES NO

36. Education, please check the highest level completed:

High School Some College Associate's Degree

Bachelor's Degree Graduate School Experience Graduate School Degree

37. Name of college/university:

38. Graduate of college with bridge program for regional airline: YES NO

39. Completed college airline internship: YES NO

40. Aviation Degree: $\quad$ YES NO

41. Non Aviation Degree: $\quad$ YES NO

42. 2 year college with aviation school: YES NO

43. 4 year university with aviation school: YES NO

44. Aviation school, no college affiliation: YES NO

45. Part 141 curriculum: $\quad$ YES NO

46. Part 61 curriculum: $\quad$ YES NO

47. Were aircraft owned by aviation school? YES NO 


\title{
Survey of Flight Instructors’ Experiences in Communication Training
}

\author{
Julie C. Hall \\ University of North Dakota
}

\begin{abstract}
A self-report survey of flight instructors $(\mathrm{N}=102)$ at an upper Midwestern university flight program was administered to gather flight instructors' reflections of their experiences in communication training. Four open-ended questions yielded information about courses or training in communication flight instructors received, experiences that helped improve their ability to communicate effectively, training in effective communication with students, and participation in crew resource management courses. Content analysis methods were used to analyze data. Instructors reported experience flight instructing, coursework, their flight instructors, FAA materials, and daily life interactions as sources of training and experience in communication. Training implications and areas for further research are discussed.
\end{abstract}

\section{INTRODUCTION}

A flight instructor's work is built on the ability to communicate. Flight instructors communicate verbally and nonverbally with their students, teaching the knowledge, skills, and attitudes needed to be a successful pilot (Federal Aviation Administration [FAA], 2008). Flight instructors impact the ultimate success of a student. The FAA's Practical Test Standards (PTS) for initial flight instructor applicants (FAA, 2009) require flight instructor applicants to demonstrate the ability to effectively communicate. As official guidance to meet the standards in the PTS, the FAA Aviation Instructor's Handbook contains ten pages covering the following topics: basic elements of communication, barriers to effective communication, and developing communication skills (FAA, 2008). Even though the FAA officially dedicates only ten reference pages specifically to the topic of effective communication for flight instructors, the ability to clearly and effectively communicate permeates all areas of competency that a flight instructor applicant is required to satisfactorily demonstrate on a practical test (FAA, 2008; FAA, 2009).

Prior to this study, the author spent some time observing flight instructors with varying levels of experience and gathered some anecdotal evidence indicating that communication patterns seemed to change when a flight instructor had more flight instruction experience. This preliminary finding prompted the author to research the topic further. The author sought studies specifically dealing with communication theoretical frameworks and flight instruction. There is a large amount of work specifically addressing communication in classroom settings (e.g., McCroskey, L. L., Richmond, \& McCroskey, J. C., 2002; Rubin, 2002) as well as studies of communication in multiple flight crewmember settings (e.g., Salas, Burke, Bowers, \& Wilson, 2001; Salas, Wilson, Burke, \& Wightman, 2006). Studies of communication in flight instruction settings proved more difficult to locate. The purpose of this survey is to provide an overview of how flight instructors perceive they learned to communicate effectively in a structured collegiate flight training environment. This survey was conducted as part of a larger study and intended to be used to guide areas of future research.

In order to better understand flight instructors' perceptions of their communication training, the following research questions were addressed in this study:

1. What kind of communication training does a typical flight instructor receive when completing a degree curriculum at one highly structured collegiate flight program?

2. Do experiences shape a flight instructor's ability to communicate?

3. When obtaining their flight instructor certificate, what training did flight instructors receive specifically geared toward communicating with students? 


\section{Have flight instructors received CRM training?}

\section{METHOD}

\section{Participants}

The target population of this study is certificated flight instructors at a structured collegiate flight training program. At the time of the survey approximately 300 flight instructor certificate holders were either employed at or students of an upper Midwestern university. A total of 102 individuals volunteered to take the study survey. The flight instructors who responded to the survey reported a range of flight experience as a flight instructor between zero hours and 6,000 hours of experience.

The FAA outlines its minimum requirements for the training of flight instructors, and variance exists from school to school as to what and how flight instructors are taught. By sampling from one location, the potential for confounding the study by introducing the variable of varied learning experiences was reduced. Admittedly, the study design limits the generalizability to the university where the survey was administered.

Of the 102 respondents, 98 survey respondents indicated that they had obtained all of their flight instructor certificates at the upper Midwestern university, three survey respondents indicated that they had obtained some of their flight instructor certificates at the university, and one respondent indicated that they had obtained all flight instructor certificates at places other than the university. In order to be eligible to take the university's course to become a flight instructor, students must have completed at least four semesters worth of prerequisite flight courses as well as the prerequisites and corequisites for the flight courses (University of North Dakota [UND], 2011a; UND, 2011b). Examples of the non-flight related required courses are: meteorology, aviation safety, and aircraft systems. Since 98 of the survey respondents indicated that they had obtained all of their flight instructor certificates at the upper Midwestern university, an overwhelming majority of the sample was subjected to similar training experiences over a period of years.

The university has a FAA-certificated Part 141 training program (Federal Aviation Regulations, 2009), it is accredited by the Aviation Accreditation Board International (AABI) (Aviation Accreditation Board International [AABI], 2010), and it is a University Aviation Association (UAA) member (University Aviation Association [UAA], 2011). In addition to the flight instructor course that includes practice instruction experiences, the college curriculum for a bachelor's degree with a major in commercial aviation at the university includes required coursework in public speaking, writing, Crew Resource Management (CRM), and a flight course in the Canadair Regional Jet (CRJ) simulator that requires crew interaction. This commercial aviation degree curriculum is well above and beyond basic FAA requirements to obtain a flight instructor certificate (FAA, 2009).

The exact dates that the survey respondents obtained their training at the university was not asked on the survey, but can be inferred from the range of flight experience reported. Some variance in training experiences may exist due to slight changes that were made to the university's curriculum over the years. To illustrate the magnitude of changes made to curricula, since 2001 the following changes were made to the commercial aviation major curriculum at the university: added and deleted a requirement for an interpersonal communication course, added and deleted an information technology course, replaced a course in air transportation with a senior capstone, and added the choice between courses in creative writing, writing non fiction, and business communication rather than requiring the business communication course (UND, 2011a; UND, 2011b). It can be assumed that the sample was subjected to a similar level of structure, rigor, and enhanced curriculum available at an FAA-certificated Part 141, AABI-accredited, UAA-member program. 


\section{Procedures and Instrument}

An anonymous self-report survey was used to collect data. The first section of the survey consisted of several closed questions regarding gender, total flight experience in hours, total flight instruction experience in hours, instructor certificates held, whether or not all flight instructor certification training was obtained at the university, and the quantity of experience obtained as a crewmember in an aircraft requiring more than one flight crewmember. The four open-ended questions in the survey used to gather qualitative data were:

1. Please describe courses or training in communication you have received.

2. What experiences do you believe helped improve your ability to communicate effectively?

3. In your training for the first flight instructor certificate you obtained, what training did you receive on communicating effectively with your students?

4. Have you participated in any crew resource management (CRM) courses? Please describe. Do you think that CRM courses are helpful and worthwhile, or is CRM something you learn more by doing?

Before launching, the survey was reviewed for clarity, ease of response, and validity by four experts including two professional pilots and two professors well-versed in research methods. In compliance with Institutional Review Board (IRB) approved procedures, study advertisements were made via mass email and poster-sized signs posted in high-traffic areas during the week of data collection.

The survey was administered over the period of one week, Monday through Friday, from 9:00 AM to 7:00 PM in a university computer lab. When survey participants arrived at the computer lab to participate in the survey, they were given an IRB-approved information sheet to review. After reading the information sheet conditions and agreeing to them, each was given a paper copy of the survey and shown to a cubicle to complete the survey. The survey took approximately 20 minutes to complete and all survey participants were compensated $\$ 5.00$ for their time. The $\$ 5.00$ amount was mentioned in all advertisements and given to all participants regardless of how much of the survey they completed. Survey forms were disseminated, collected, and stored by the principal investigator according to approved procedures.

Content analysis methods were employed to analyze the qualitative data obtained on each of the four questions. The same framework for analysis was employed on each question individually. Responses were read by the principal investigator, and the words written by respondents for ideas and concepts in responses were recorded in theme clusters. All participants responded to each of the four questions, and content from the responses revealed common themes. Theme clusters were developed based upon the data from the responses received and vary from question to question. The number of responses in each cluster was also noted to determine the cluster with the largest number of responses to each question. Due to the ability of a respondent to indicate multiple responses on a single question that fall into multiple independent theme cluster groups, some of the proportions of responses to a question add up to more than $100 \%$.

\section{Limitations}

The limitations associated with qualitative research, content analysis methods, and self-report survey methods apply to this survey. Some of the possible limitations are: the inability to read some of the respondents' handwriting, the possibility of creating a coding scheme that has too many or too few theme clusters, and the possibility of misinterpretation. All respondents to this survey were employees or students of a single university, and as such, their responses may only apply to the affiliated university. Survey participants volunteered to participate, and their participation may be influenced by things such as 
individual interpretation of the open-ended questions, individual interpretation of the terms used in the questions, biases, and the desire to respond in a socially acceptable manner.

\section{RESULTS}

\section{Question 1: Courses and Training in Communication}

The first open-ended question on the survey was, "Please describe courses or training in communication you have received.” Ninety eight of 102 participants responded to this question by stating aviation-specific and general education courses at the Midwestern university, and the remaining four respondents did not include any university coursework in their responses. The university courses mentioned included: Aviation Safety, CRM, Advanced Aircraft Operations/CRJ course, Flight Instructor courses including Certified Flight Instructor (CFI), Instrument Flight Instructor (CFII) and Multi-engine Flight Instructor (MEI), Human Factors, Business Communication, Public Speaking, and Interpersonal Communication. A few respondents elaborated that the group work required in upper-level courses contributed, and that all flight courses included elements of learning how to communicate with others. Other university coursework viewed as beneficial were foreign language courses and psychology courses. In addition to university coursework, a few other themed responses were made in response to Question 1 by five or fewer respondents each: aviation training outside the university, leadership courses and seminars, employer courses, high school, and working with others.

\section{Question 2: Communication Experiences}

The second open-ended question on the survey asked, "What experiences do you believe helped improve your ability to communicate effectively?” The largest groups of responses are displayed in Figure 1.

Figure 1. Question 2 Responses

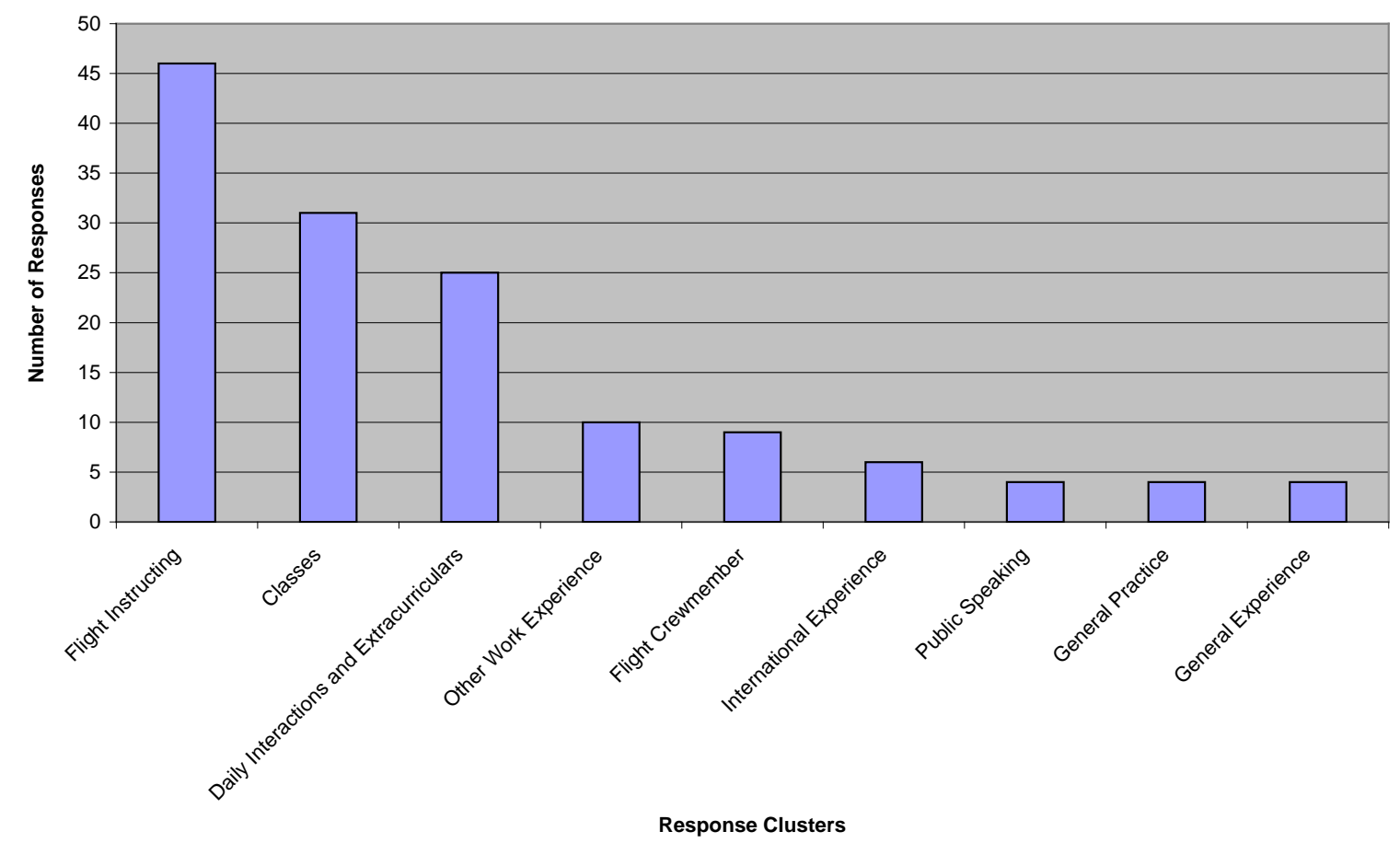

Figure 1: Question 2 Responses 
A few additional responses that did not fit into groupings were: observing communication in a cockpit jump seat, self study by reading books, leadership training, the university's standardization of communication, and the idea that personality is the factor that makes people more or less expressive.

Forty-six of the survey responses made reference to experience flight instructing as an experience that improved their ability to communicate effectively. Some respondents elaborated that they gained comfort and confidence through their experiences. Some mentioned interactions with air traffic control and radio communications. A few mentioned the high-stress environment and one expressed the need to be patient while instructing. Also mentioned were the interactions with different levels and types of students as well as interactions with other flight instructors. One expressed that flying with a low time pilot forces clear and effective communication. While coursework may have helped these survey respondents get off to a start, the group of individuals who responded that flight instruction was helpful had some quotes that illustrate their views on gaining actual experience: "Working with students on a day to day basis helps a lot, sort of a sink or swim method of learning," and, "Actually flight instructing for the first time was the best experience for effectively communicating with students. Even though a flight instructor attempts to act like a student, it is no substitute for actually teaching someone.” Thirty-one respondents indicated that their classes including aviation and communication coursework helped them. In particular, coursework in CRM and CRM related topics were mentioned in response to this question, as well as the CRJ course. Students in the CRJ course are required to complete simulator sessions as part of a flight crew.

Twenty-five of the respondents indicated that daily life social interactions and extracurricular activities enhanced their ability to communicate. As an example of daily social interactions, three people specifically mentioned living with people or having roommates as experiences that have shaped their ability to communicate. Social interactions, participation in clubs and social functions, and playing sports were all mentioned. A few people mentioned conversing with friends who have different communication styles and defending ideas in group settings. One mentioned that being social throughout their life shaped their ability to communicate, and another added that practice communicating in a diverse population at home helped. One elaborated that talking with others about misunderstandings or miscommunications was helpful. One respondent remarked the following views on everyday communication: "Experiences in leadership outside of school in clubs and the (organization name) have better prepared me to communicate than any class. It is hard to teach someone to relate to people.”

International experiences included both international travel and working with international flight students, which some noted was an experience that helped improve their ability to communicate clearly. Some mentioned the experience working as a member of a flight crew was beneficial, and for purposes of this analysis, that interaction experience is grouped with working as a flight crewmember in the training environment since references were made to the actual flight practice in the CRJ simulator. Ten of the respondents indicated that work experiences in jobs outside of aviation were beneficial. Those who responded with information about their jobs indicated that they interacted often with people, such as sales and refereeing sports, or worked in team environments such as being in the military.

The following response clusters were mentioned by four respondents each as things that enhanced their ability to communicate: additional opportunities to engage in public speaking, practice in general was helpful, and experience in general. There were additional responses that did not fit neatly into the groupings. The responses included: observing communication in a cockpit jump seat, self study by reading books, leadership training, the university's standardization of communication, and personality.

\section{Question 3: Flight Instructor Communication Training}

The third open-ended question posed on the survey was, "In your training for the first flight instructor certificate you obtained, what training did you receive on communicating effectively with your students?” Responses to this question tended to fall into one of two overarching categories: responses that centered 
on the method of delivery of the training received, and responses that centered on the content of the training received. Figure 2 illustrates the groupings of responses that were clustered according to the method or delivery of communication training.

Figure 2. Question 3 Method or Delivery Responses

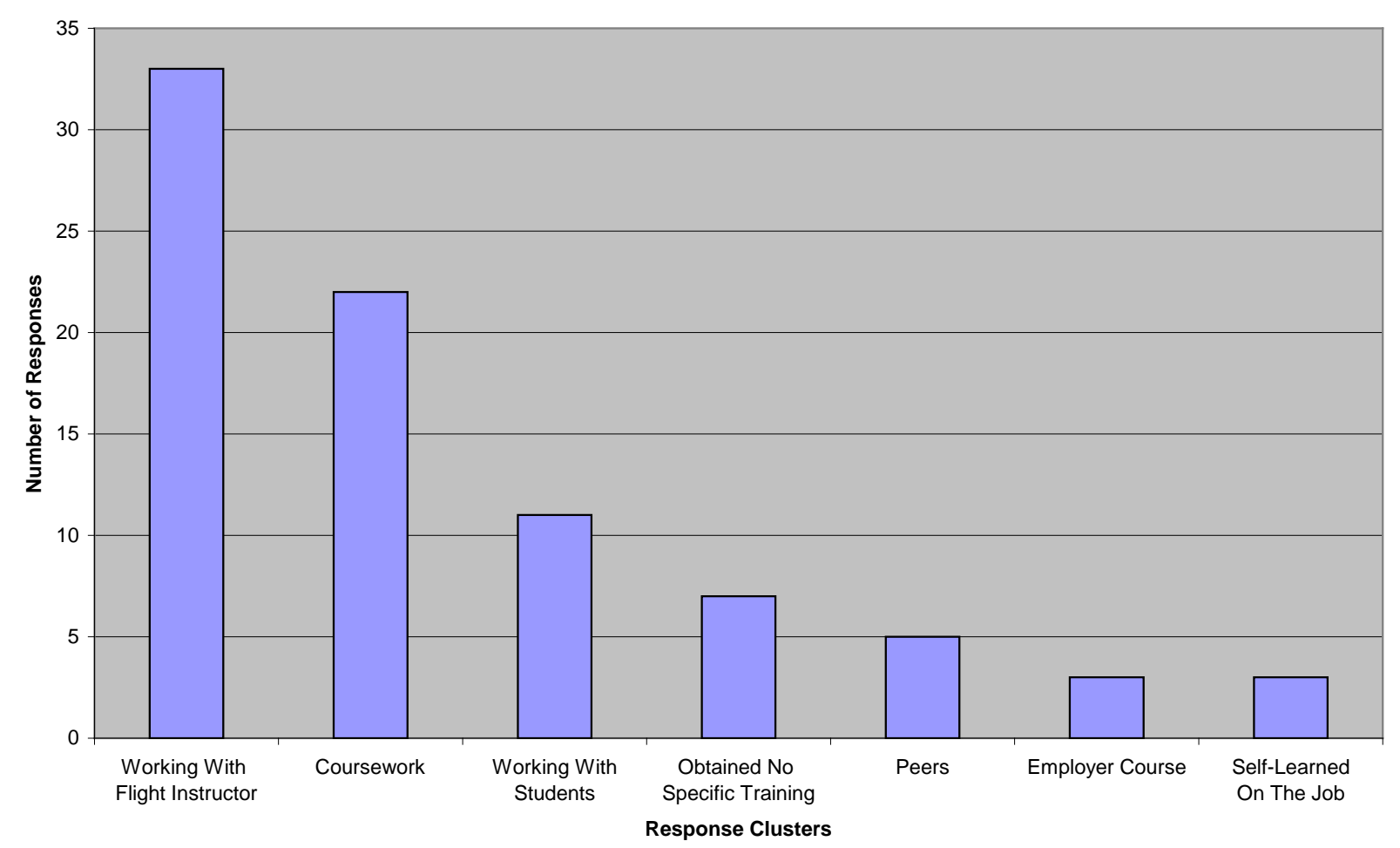

Figure 2. Question 3 Method or Delivery Responses

In terms of the content of training, the main response was either the Aviation Instructor's Handbook published by the FAA (2008) or the fundamentals of instruction (FOI) material contained inside that publication. Responses indicating the university CFI course and other courses such as CRM were counted in the overarching group as methods of delivery, but have also been considered in the content category as many of the responses did not elaborate on the content beyond listing their participation in the courses. University courses are assumed to have content as each course has a syllabus outlining its content. Due to the content of the input that flight instructors provide during a typical flight lesson involving practice flight or practice ground instruction, working with a flight instructor was not only considered in the overarching group as a method of training delivery, but also in the training content group. The types of responses clustered as content when working with a flight instructor included responses such as the instructor acting like a student and instructor’s feedback. See Figure 3 for responses regarding content. 
Figure 3. Question 3 Content Responses

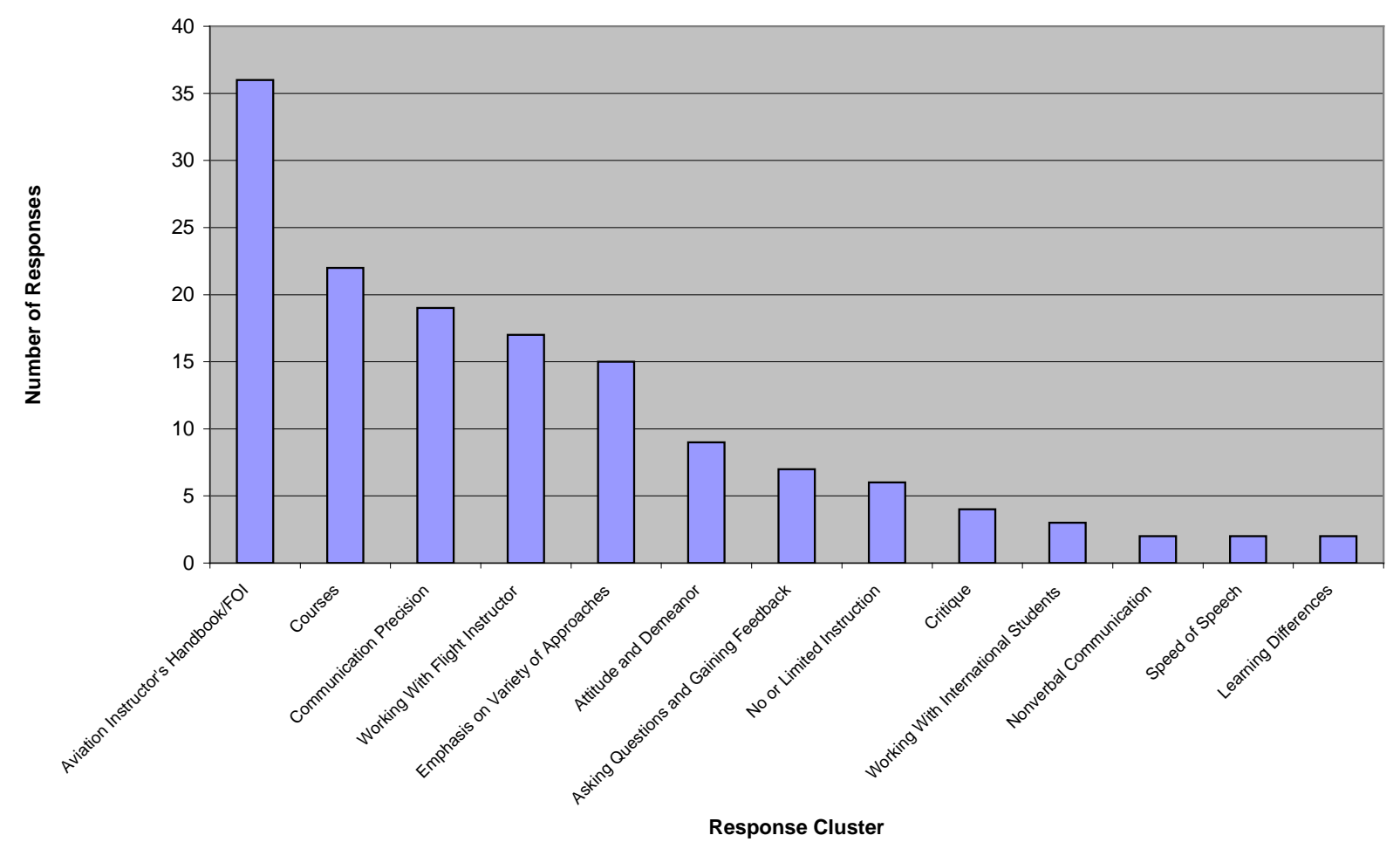

Figure 3. Question 3 Content Responses

Other ideas that received mention regarding training content were: FAA publications, books, conflict, visual communication, barriers to communication, preparation for lessons, and defensive positioning. When this question is viewed in combined terms of delivery and content, the two most popular answers were applicants working with their flight instructors, and the FAA's publication the Aviation Instructor's Handbook (2008). While the FAA's Aviation Instructor's Handbook (2008) is a publication with a finite, defined body of content delivered to all who read it in a uniform manner, flight instructors differ with regard to the content and delivery of material taught. The following quotations from survey respondents illustrate some of this variance in communication instruction and feedback given by flight instructors to their flight instructor applicant students:

"Instructor attempted to be a difficult student, essentially not understanding things. Making me try different ways of teaching/comm. Otherwise it was based on instructors' thoughts on how I did.”

“Extremely little. Periodically my CFI instructor would 'feign' disinterest in order to force me to directly engage her with the briefing."

"When I first started CFI, I used advanced aviation terms. My instructor simply said, 'I don't know ANYTHING about airplanes/flying. What is that?' It helped me to be more careful in word choices.”

"Very little, I received much more training from my CFII flight instructor. He taught me to be precise and assertive, and I learned to judge the feedback the student is giving." 
"My flight instructor emphasized the need to get feedback from a student to know they really understand a concept. Also that it is important to teach something correctly the first time. The FOI communication chapter was also taught.”

"The F.O.I. provides some tips on dealing with students and learning styles, but much of it seems very simplistic. The best resource is simply prior instructors who were either good or bad, and using that as a guide.”

\section{Question 4: CRM Opinions}

The final open-ended question posed on the survey was, "Have you participated in any crew resource management (CRM) courses? Please describe. Do you think that CRM courses are helpful and worthwhile, or is CRM something you learn more by doing?” The most popular answer theme, with 48 respondents, was that they took a CRM course at the university, the CRM course was beneficial in providing a foundation of learning, and that CRM is something that must be further learned by doing after gaining the foundation. Another 35 respondents indicated that they had taken a CRM course at the university and found it beneficial. See Figure 4 for responses to Question 4.

Figure 4. Question 4 Responses

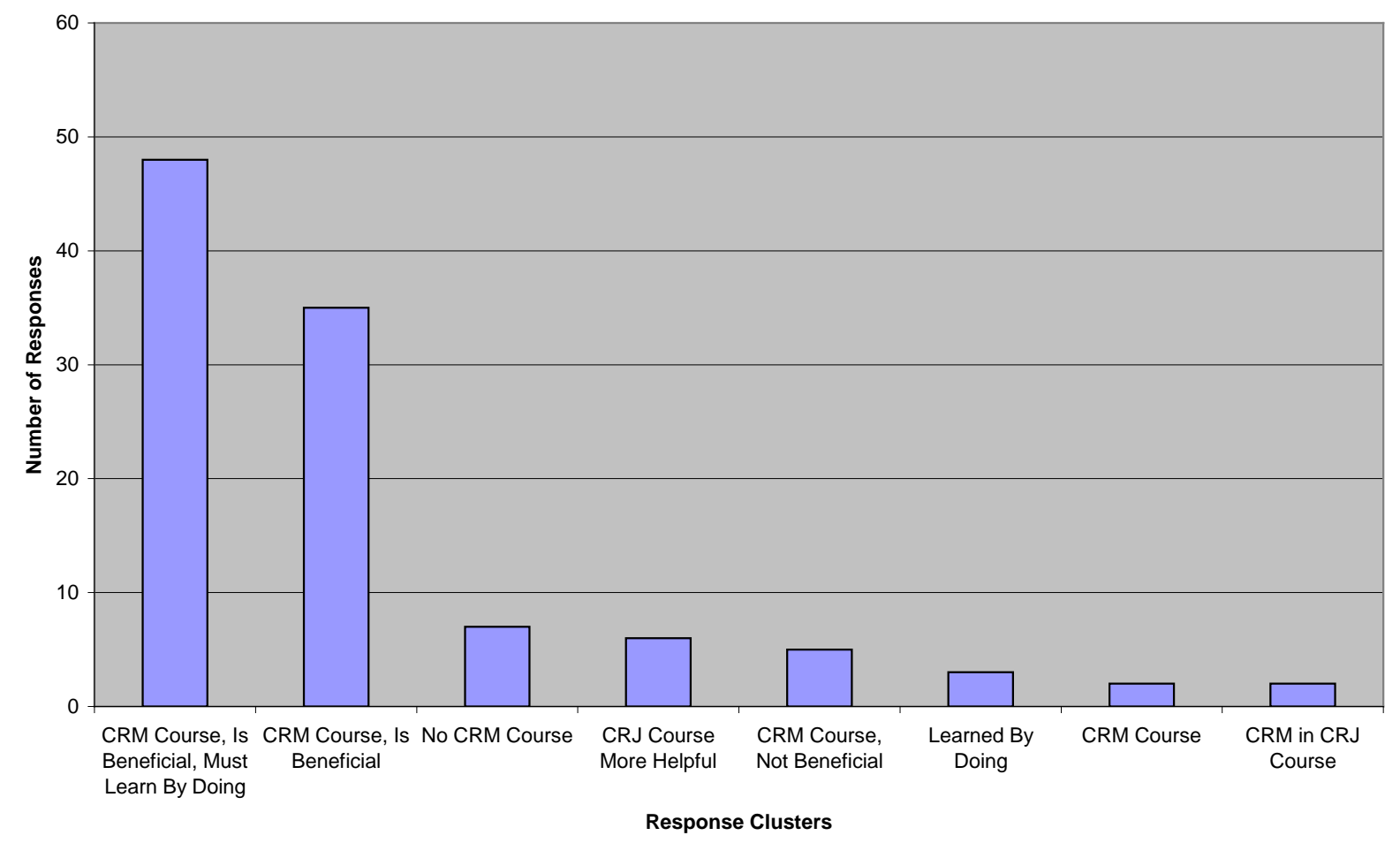

Figure 4. Question 4 Responses

There was much discussion about CRM in the context of multiple-crewmember settings from survey respondents, but very little mention of flight instruction in responses to this question. Two respondents specifically mentioned that CRM courses did not address flight instructor/student dyadic interactions. Other comments made in response to this question were that the instructor is important in the success of a CRM course, and that observing flight crews was beneficial. 


\section{DISCUSSION}

When examined as a whole, the grouped responses to the questions reveal some patterns and spark new questions. The top three grouped responses to Question 2 regarding experiences that helped improve the ability to communicate were: experience flight instructing, classes, and daily life interactions and extracurricular activities. It is not entirely surprising that experience flight instructing was the top answer to Question 2 as every respondent in this sample is a certificated flight instructor. What remains unanswered is the following question: What are flight instructors learning by actually instructing? It is possible that the answer to this question includes concepts that are not currently included in formal coursework or published FAA materials. The third most frequent response group was daily life interactions and extracurricular involvement, indicating that social activities can have an impact on a person’s ability to communicate in a variety of settings, including professional settings.

Question 1 asked specifically about courses or training, and Question 2 asked about experiences. Even though Question 2 asked specifically about experiences, one third of the respondents still mentioned their university courses as experiences that helped their ability to communicate. Collegiate aviation programs need to be mindful of students' reliance on the curriculum and build a curriculum that addresses the need for both general interpersonal communication skills and specialized aviation communication skills. Ideally, students should possess a solid foundation of basic interpersonal communication skills early in their college career. Once a solid foundation of interpersonal communication competence is built, specialized CRM communication and flight instructor communication skills can be addressed in upper division courses.

The responses to Question 3's inquiry about the training received in communicating effectively with students make it clear that the FAA's publications, especially the content considered the fundamentals of instruction in the Aviation Instructor's Handbook (FAA, 2008) are the basis of much of what this group of flight instructors considered regarding communication during their training to become a flight instructor. Flight instructors were also regarded as important sources of information as many responded that ideas and feedback provided by instructors comprised much of what was learned about instructional communication. While great value was placed on what flight instructors had to say about instructional communication, it is difficult to effectively define what knowledge flight instructors are bestowing upon students beyond some smaller idea clusters and some of the quotations shared. The material in the FAA's publication is defined; the material passed on by flight instructors is not and varies. What communication skills are flight instructor applicants learning from their instructors? It is possible that the material flight instructors cover with their students includes aspects of interpersonal communication competence or instructional communication techniques that are more detailed than addressed by coursework or the FAA's published materials.

Several other ideas of content regarding interpersonal communication were shared by survey respondents in response to Question 3, though it is not entirely clear whether those ideas originated from flight instructors or FAA publications. Another observation of the specific communication concepts mentioned in content-related responses to Question 3 is that a larger number of survey respondents indicated that material regarding communication delivery (e.g. communication precision, attitude projection) was covered than the number of survey respondents indicating that responsiveness behaviors (e.g. listening to student, interpreting student feedback) were covered. It is possible that the responsive communication behaviors are some of the more subtle behaviors that flight instructors learn through experience.

Flight instruction is only mentioned in a few instances in responses to Question 4's question about participation in CRM courses. There was minimal overlap of mentions of flight instruction with CRM, 
possibly illustrating that respondents compartmentalized CRM separately from flight instruction communication.

\section{Future Directions}

Much research is yet to be done that could benefit the communication training of flight instructors. Two of the important questions yet to be better answered were mentioned above. What are flight instructors learning by actually instructing? Also, what communication skills are flight instructor applicants learning from their instructors? A greater understanding of the content of the material being verbally passed from one generation of flight instructor to the next generation through one-on-one training interactions would help to define useful concepts that are being perpetuated outside of the FAA's required materials. Since so many respondents indicated that they learned by actually flight instructing, an examination of the differences in communication skills between a newly certificated flight instructor and a highly experienced flight instructor would help define what beneficial communication skills are learned through flight instruction experience. Having a more detailed, defined set of instructional communication skills beneficial for flight instructors could help develop more comprehensive curricula and training materials for flight instructor applicants in pursuit of a flight instructor certificate. More importantly, newly certificated flight instructors might be more comprehensively equipped to communicate with their first students.

Beyond learning through actual flight instruction, a large number of survey respondents indicated reliance on coursework for training in effective communication. Currently, entire courses are devoted solely to CRM, while communication concepts useful to a flight instructor are sprinkled within the ground school and flying portions of a flight instructor course. While some CRM concepts may be useful in flight instruction settings, assuming that a CRM course helps arm a flight instructor for their position would be difficult since CRM communication concepts and flight instruction communication concepts involve two different dyadic relationships.

An audit of a curriculum, including the communication concepts addressed in individual courses, could be beneficial in building a comprehensive communication skills curriculum that better equips future aviation professionals for the subtleties of different types of interpersonal communication. It cannot be assumed that all incoming college students will possess the baseline interpersonal communication skills upon which to build CRM communication and flight instruction communication skills. A communication skills exam upon entrance to a college program, similar to a math placement exam, could serve as a tool to identify a student's shortcomings in communication skills. Development of such an exam could be directed by skills identified as important, and early general education requirements could fill potential gaps and solidify a student's communication skills foundation.

Studying interpersonal communication in flight instruction and strengthening interpersonal communication curricula may seem like daunting tasks as much work would be required to gain clear insights into the questions raised above. Scholarship in communication and based on communication theoretical frameworks offers ideas and instruments that could possibly be beneficial in studying communication in flight instruction. For example, theories centered on interpersonal communication and some of the instruments developed by McCroskey and Richmond (1996), such as the SocioCommunicative Orientation Scale (SCO) and the SocioCommunicative Style Scale (SCS), could be useful (Richmond \& McCroskey, 1990). Dozens more communication theoretical frameworks and instruments exist that could be useful in studying communication in flight instruction settings. Interpersonal communication curricula could also be strengthened with the theoretical frameworks and curricula that have been forwarded by communication scholarship. Morreale and Backlund (2002) provide an overview of the concepts in communication curricula scholarship. Communication in flight instruction could be strengthened by appropriate integration of communication scholarship in aviation. 
Many survey respondents indicated that everyday interactions and involvement in extracurricular activities were beneficial in shaping their ability to communicate with others. Aviation students no doubt spend a large amount of time flying, attending class, and studying. It is possible that a typical student's college interpersonal relationship experiences have been altered by the prevalence of electronic communication such as internet social media and text messaging. A survey of aviation students to determine whether they are involved in at least one extracurricular or work activity, to determine what other demands are placed on their time, and to determine typical communication patterns could illustrate what a typical student is exposed to in terms of opportunity to learn to communicate through practice interacting. It is true that an aviation student's involvement in intramural sports may not have a direct correlation with how well they can fly an instrument approach, but it may serve as a nonthreatening method of helping a typical student learn how to be a leader, a follower, or merely play well with others in a cockpit. 


\section{REFERENCES}

Aviation Accreditation Board International. (2010). Aviation Accreditation Board International. Retrieved November 10, 2010, from http://www.aabi.aero

Federal Aviation Administration. (2008). Aviation instructor's handbook. (FAA-H-8083-9A). Washington, DC: U.S. Department of Transportation, Federal Aviation Administration.

Federal Aviation Administration. (2009, March 16). Flight instructor practical test standards (FAA-S-8081-6C, Changes 1, 2, 3, 4). Washington, DC: U.S. Department of Transportation, Federal Aviation Administration Flight Standards Office.

Federal Aviation Regulations, 14 C.F.R. § 141 (2009).

McCroskey, J. C., \& Richmond, V. P. (1996). Fundamentals of human communication. Prospect Heights, IL: Waveland Press, Inc.

McCroskey, L. L., Richmond, V. P., \& McCroskey, J. C. (2002). The scholarship of teaching and learning: Contributions from the discipline of communication. Communication Education, 51, 383-391.

Morreale, S. P., \& Backlund, P. M. (2002). Communication curricula: History, recommendations, resources. Communication Education, 51, 2-18.

Richmond, V. P., \& McCroskey, J. C. (1990). Reliability and separation of factors on the assertivenessresponsiveness scale. Psychological Reports, 67, 449-450.

Rubin, L. E. (2002). Binocular vision for communication education. Communication Education, 51, 412419.

Salas, E., Burke, C. S., Bowers, C.A., \& Wilson, K. A. (2001). Team training in the skies: Does crew resource management (CRM) training work? Human Factors, 43, 641-674.

Salas, E., Wilson, K. A., Burke, C. S., \& Wightman, D. C. (2006). Does crew resource management training work? An update, an extension, and some critical needs. Human Factors, 48, 392-412.

University Aviation Association. (2011). University Aviation Association. Retrieved March 18, 2011, from http://www.uaa.aero/

University of North Dakota. (2011a). Previous academic catalogs. Retrieved March 27, 2001, from http://www.und.edu/dept/registrar/catalogs/catalogs.htm

University of North Dakota. (2011b). Welcome to the 2009-2011 UND academic catalog. Retrieved March 27, 2011, from http://www.und.edu/dept/registrar/catalogs/catalog/index.htm 